\title{
Female Labour Force Participation and the Child Support Grant in South Africa
}

\author{
Katherine Eyal*and Ingrid Woolard ${ }^{\ddagger}$
}

August 2, 2010

We estimate the effect of the child support grant on mothers' labour supply in South Africa. Identification is based on the use of specific samples, such as black mothers, aged 20 to 45, whose youngest child is aged within 2 years of the age eligibility cut-off, and unanticipated variation over the years in the age eligibility cut-off. Balancing tests across the age cut-offs are used to show there are no significant differences between mothers of eligible and ineligible children in the samples used, over the years. Different techniques are used to estimate the effect of the child support grant from many angles, including simple OLS as a bench mark, a difference in difference estimator, using appropriately constructed treatment and control groups, instrumental variables estimates, and descriptive analysis. The effect of having an age eligible child is indeterminate, and depends on whether the shock of additional income is seen as transitory or permanent. Low income households find grant receipt to be more important, with large effects on employment probability. Many robustness and specification checks are used, including placebo regressions in the pretreatment years, to ensure the estimated effect is not due to age or another variable.

\footnotetext{
*Southern Africa Labour \& Development Research Unit (SALDRU) Affiliate. Doctoral Candidate, Hebrew University of Jerusalem. Lecturer, School of Economics, University of Cape Town, Private Bag, Rondebosch 7701, South Africa. Tel: +27 21650 5784. katherine.eyal@uct.ac.za

${ }^{\dagger}$ Co-PI: National Income Dynamics Study. PD Hahn Level 7. Southern Africa Labour \& Development Research Unit (SALDRU). Associate Professor, University of Cape Town. Private Bag, Rondebosch, 7701, Tel: +27 21650 5955, Fax: +27 216505403 . Ingrid.Woolard@uct.ac.za

${ }^{\ddagger}$ We would like to thank Jorge Aguero, Cally Ardington, and Nicola Branson, for many useful comments, and participants of the SALDRU Seminar Series at UCT.
} 


\section{Contents}

1 Introduction 3

2 The Child Support Grant: History of Allocation 4

3 Literature Review $\quad 4$

3.1 Existing Literature on Grant Takeup and Effects . . . . . . . . . 4

4 Theory $\quad 7$

4.1 Potential Mechanisms Through Which the Causal Effect Operates 7

4.2 Static Model of Labour Supply . . . . . . . . . . . . . . . . . . 7

4.3 Including Fixed Costs of Working . . . . . . . . . . . . . 8

4.4 Long Term Effects . . . . . . . . . . . . . . . . . . . . 8

5 Data 9

5.1 Samples and Terminology . . . . . . . . . . . . . . . . 10

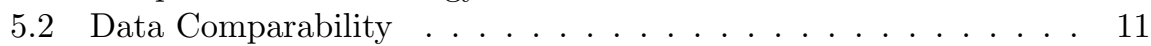

5.3 Estimation Issues . . . . . . . . . . . . . . . . . . . 12

5.3.1 Means Test vs. Controlling for Household Income . . . . 12

5.3 .2 Correlation ... . . . . . . . . . . . . 12

5.4 Heterogeneity in Treatment Effects . . . . . . . . . . . . . . . 13

6 The South African Labour Market 13

6.1 Sample Means . . . . . . . . . . . . . . . . . . . 13

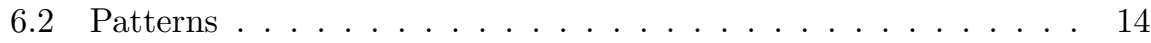

6.3 Patterns in Receipt . . . . . . . . . . . . . . . 16

7 Identification $\quad \mathbf{1 8}$

7.1 Strategy . . . . . . . . . . . . . . . . . 18

7.2 Level Specification . . . . . . . . . . . . . . . . . . 18

7.3 Difference in Difference . . . . . . . . . . . . . . . . . . . 20

7.4 Modified Differences in Differences . . . . . . . . . . . . . . 23

7.5 Regression Discontinuity . . . . . . . . . . . . . . . . . 24

7.6 Instrumental Variables . . . . . . . . . . . . . . . . . . . . 26

7.7 Mechanisms ..................... 27

8 Discussion $\quad \mathbf{2 8}$

8.1 Connection to the Theory . . . . . . . . . . . . . . . . 28

8.2 Other Issues . . . . . . . . . . . . . . . . . . . . 28

9 Conclusions $\quad 29$ 


\section{Introduction}

Following the Lund Commission in 1996, the state maintenance grant was phased out for 400000 beneficiaries, and South Africa's child support grant was introduced, with the goal of removing racial and gender inequality in the social support system, effectively targeting poor children no matter their household status, improving nutrition in the critical early years, and being able to scale relatively easily to large numbers of recipients (Lund 2008), unlike conditional cash transfer programs.

Rollout began in April 1998, with various conditions, and by 2000 the grant was effectively being distributed for children below the age of 7 , subject to a means test, of 800 rand in urban areas, and 1100 rand in rural areas. However initial take-up was low, estimated at only ten percent in 2000 , but increasing to $63 \%$ by 2005 (Samson et al. 2008).

The grant is distributed to the child's primary caregiver, and is intended to follow the child. It is paid out into bank accounts, at post offices, super markets, and CPS pay points. In early 20037 and 8 year olds gained access, the following year 9 and 10 year olds, and in 2005 those under 14. Meanwhile the means test remained unchanged, and thus many would be recipients may have lost the grant, or never applied for it, due to inflation. Budlender, Rosa \& Hall (2005) calculate that in 2004, to keep pace with inflation, the means test should have been set 1123 and 1544 rand.

In October 2008 the means test was changed to reflect the effect of inflation, with the new rule setting level at ten times the level of the grant, thus increasing the number of would be recipients. In February 2010 it was announced that all children under the age of 18 would gain access, conditional on the means test. The value of the grant in October 2008 was 220 rand, approximately 30 US dollars (Delany et al. 2008).

The CSG may have many positive impacts. It may help to ensure food security, aid parents in buying school uniforms and paying school fees, and thus support enrollment and attendance, increase access to credit by raising individual's trustworthiness, alleviate poverty in the household, raise women's bargaining power in the household, and possibly fund job search and or day care or creche for the beneficiary, enabling the mother to work.

This paper investigates this last possibility, that of the effect of the child support grant on a mother's labour market status. Does labour force participation or labour supply change in response to grant receipt? Answering this question is complicated, due to the endogeneity of the child support grant variable, and whether recipients view access as temporary or permanent. Receipt is correlated with income, education, and race, amongst other factors. Few papers have addressed this endogeneity problem satisfactorily, as it is hard to find a sample in which CSG can be considered to be randomly assigned.

In addition, there is little in the literature regarding the effect of the child support grant on the mothers of beneficiaries. We consider three outcomes initially: labour force participant, employment probability, and unemployment (conditional on being a participant). It is difficult to find good child outcomes which are not correlated with age and which are recorded in the data, and a rich literature surrounding the effects on beneficiaries already exists.

This paper is structured as follows. Section 2 provides detail of the history of the rollout of the child support grant. Section 3 discusses the current literature 
around grant receipt in the South African context. Section 4 sets up a simple static model of labour supply with transaction costs to explain how the CSG might affect labour market status. Section 5 describes the data used, the various sample definitions, and estimation issues. Section 6 examines the patterns present in the South African labour market over the past 12 years, through the use of graphs. In Section 7, the various strategies used for identification, and their motivations are covered, as well as estimation results. Section 8 discussed, and section 9 concludes.

\section{The Child Support Grant: History of Alloca- tion}

In table A11, the amounts, dates of change, and age cut-off values are shown for the old age and disability grant, the foster care and state maintenance grant, and the child support grant. This data is collated from SOCDEV data. The Child Support Grant was introduced in 1998 to all children under 7. The grant was set at R100 per child, with a means test of R800 in urban areas, and R1100 in rural/informal areas. The means test included the income ofthe child's caregiver and their spouse. The grant was extended in 2003 to 7 and 8 year olds, and increased to R160. In 2004, it was again extended to 9 and 10 year olds, and increased by $\mathrm{R} 10$ to R170.

In 2005, the age eligibility cutoff was raised to 14 , and the grant increased to R180. In 200814 year olds obtained access to the grant, set at a level of R210. For the first ten years since inception, the means test was kept the same, which meant that due to creeping inflation, many families may have gradually lost access to the grant, and the grant may have been less meaningful in monetary terms. The means test was finally changed in October 2008 to be ten times the grant amount. 2010 saw a final extension to all children under the age of 18, and an increase to R250.

A note on terminology. We refer to the child who is designated to benefit from the grant as the beneficiary, and the mother or other caregiver who receives the grant, as the recipient.

\section{Literature Review}

\subsection{Existing Literature on Grant Takeup and Effects}

Initially many infrastructure problems plagued the rollout of the grant (Hunter 2004, Hunter \& Adato 2007b, Budlender et al. 2005, Aguero et al. 2009, Goudge et al. 2009, Delany et al. 2008). Welfare offices in 2003 were understaffed, and lacking vital equipment. The system of grant application differed from office to office. A lack of postal addresses among potential recipients complicated initial applications. Multiple applications per child were also a problem (Hunter 2004). Knowledge was widespread regarding the grant's existence, but the exact details of how to apply, and who could apply were not widely known (Hunter $\&$ Adato 2007a). However, rejections based on the means test were very rare. Knowledge of the correct age cut-offs in 2003 and 2004 were not accurate (Hunter \& Adato 2007b). 
Many cite lack of documentation as the reason for refusal of their application, or for not applying (Goudge et al. 2009, Leibbrandt et al. 2010, Woolard et al. 2009, Delany et al. 2008). The time cost of acquiring the necessary documents was estimated at 8 full hours (Budlender et al. 2005). In 2003, the time to obtain the grant was 3 or more months. Receiving the grant also took many hours spent in queues at paypoints (Hunter 2004).

The number of children eligible, and takeup rates, are also discussed. Using 2004 KIDS data, Budlender et al. (2005) estimates that two thirds of age eligible children are also income eligible. Case et al. (2005) find low takeup in all age eligible children, of $33 \%$, but much higher takeup among the very poor. By 2008 , takeup was approximately $60 \%$ of all children under the age of 15 (Woolard et al. 2009). Receipt in children under six months is low, but increases thereafter. It appears that non biological caregivers find it very hard to apply for the grant and often give up (Delany et al. 2008). The majority of caregivers are recorded as the mother, even if the mother is non resident, possibly due to fear of an unsuccessful application (Aguero et al. 2009). Approximately 10\% of recipient caregivers in the NIDS data set are not resident with the targeted child(Woolard et al. 2009).

Grant receipt automatically exempts individuals from paying hospital costs which may mitigate illness shocks. Grants may also make an individual more trustworthy and thus more able to draw on social networks in times of need (Goudge et al. 2009, Hunter \& Adato 2007a). Interestingly enough, $50 \%$ of mothers do not tell their partners they are receiving the grant (Hunter \& Adato $2007 a)$.

The literature of the effects of grant receipt has tended to focus on child outcomes, such as school attendance, child hunger, weight and height z scores, and child labour amongst others (Samson et al. 2008, Williams \& Samson 2007, Aguero et al. 2009, Budlender \& Woolard 2006, Boler 2007, Samson et al. 2004). There are few child outcomes for children below school going age in particular. Other studies have focused on the effect on grade repetition, incidences of illness, and creche or daycare attendance (Budlender, Burns \& Woolard 2007). These studies tend to include many controls in their regression specifications, in an attempt to reduce omitted variable bias. Budlender \& Woolard (2006) find the grant is associated with increased grade repetition, and less illness. Budlender \& Woolard (2006) find a small positive effect of receipt on attendance, even for children who are non recipients, but reside with grant recipients. Williams \& Samson (2007) do not find these coresident effects. Using KIDS data, Boler (2007) finds pension or CSG receipt does not affect primary school completion rates, but it does appear to protect boys from dropout. Most studies find increased daycare attendance among beneficiaries (Budlender \& Woolard 2006, Boler 2007).

The causal path through which the CSG may affect school attendance may well be through nutrition, which is documented by Yamauchi (2006), using KIDS data.

A particular problem has been the difficulty of working with, and comparing across various data sets available, due to incorrect assignment of the grant between caregiver and recipient, and lack of specific data on grant receipt (Budlender \& Woolard 2006, Budlender et al. 2005, Williams \& Samson 2007). The Labour Force Survey does not include data on grant receipt. NIDS 2008 wave 1 includes detailed information on grant receipt, and the precise nature 
and identification of the caregiver/recipient. The General Household Survey collects data on grant receipt for the beneficiary, and the mother, but does not explicitly link the child and the caregiver. KIDS data does *** (INGRID CAN YOU FILL IN)

There is a large descriptive literature, from KIDS, GHS, NIDS and other data, informing us as to the nature of child support grant beneficiaries and recipients (Budlender et al. 2007, Aguero et al. 2009, Hunter \& Adato 2007a, Delany et al. 2008). Recipients households are likely to be larger, have less income, obviously higher grant income, have less educated members, fewer assets and employed members, and more likely to be situated in rural areas. Recipients are overwhelmingly African and female (Delany et al. 2008). Grant receipt does have positive poverty alleviating effects (e.g. Samson et al. 2004, Triegaardt 2005, Leibbrandt et al. 2010). However Hunter \& Adato (2007a) note a drop in remittences to households after receipt begins. Samson et al. (2004) find that social grants may result in unfortunate household formation which preclude successful job search, however grants may also be used to fund job search

Rates of receipt are lower for orphans, and for maternal orphans in particular (Leibbrandt et al. 2010, Woolard et al. 2009, Case \& Ardington 2006). Cash grants mitigate the effect of being an orphan on educational outcomes but do not eliminate it in KIDS data from 2004, (Boler 2007), and Africa Centre data from 2004 (Case \& Ardington 2006). Timaeus \& Boler (2007) find the effect is effectively cancelled out by grant receipt, in a larger sample from KIDS 2004.

An interesting question is how or whether grant income is shared in the household, and what it is spent on. Delany et al. (2008) find that the CSG is found is pooled with other household income in about half of all cases. The authors find increased spending on food for recipients compared to eligible non recipients, as well as uniforms and school fees.

Some studies have attempted to use matching methods, constructed control groups, or regression discontinuity methods, to identify the true causal effect of grant receipt, with varying degrees of success (Samson et al. 2008, Aguero et al. 2009, Case et al. 2005, Ranchod 2006, Williams \& Samson 2007). Samson et al. (2008) create a panel data set from General Household Survey waves 2002 to 2004. They compare children who were age eligible, but did and did not receive the child support grant. The grant is found to reduce child hunger and increase school attendance among beneficiaries. Using continuous treatment estimation strategies, Aguero et al. (2009) find a significant and positive effect on height for age during the first three years of life. The estimates condition on a measure for eagerness of the mother. Case et al. (2005) use a control group of older siblings, and find CSG receipt correlated with higher school attendance, but no attempt is made to control for imbalanced treatment and control groups, or the eagerness of mothers. Ranchod (2006) finds lower labour participation among elderly pension recipients, using a discontinuity approach in the 2000 LFS and IES data. These effects may reflect a simultaneity problem. It is not clear that households on either side of the discontinuity point are similar in characteristics, a key assumption for identification.

Grant receipt may encourage fertility, in particular among teens. Makiwane, Desmond, Richter \& Udjo (2006) use many datasets ${ }^{1}$, but find no pattern be-

\footnotetext{
${ }^{1}$ The 1995 and 1998 October Household Surveys, 1998 South African Demographic and Health Survey, the 2001 Census, and the SOCPEN CSG receipt data.
} 
tween fertility and grant receipt, moreover few teen mothers report grant receipt. The authors claim teen fertility is levelling off, however they make this claim based on 2003 DHS data, which has been discussed as having particularly unreliable fertility estimates.

Some papers have examined the effect of grants on labour force participation, however mostly focusing on the effect of the old age pension, which is much larger than the child support grant (Bertrand, Sendhil \& Miller 2003, Eyal \& Keswell 2008, Posel, Fairburn \& Lund 2006, Ranchod 2006, Williams \& Samson 2007). Some negative effects on labour force participation are found, which however decrease in size from 1993 to 2001, and disappear once migrant workers are taken into account. Williams \& Samson (2007) make use of the step pattern in age eligibility from 2002 to 2005 , and find increased broad labour force participation among participants. Their identification is based on a sample of mothers whose eldest child becomes eligible, which disregards the effect of younger children who may affect labour force participation equally.

\section{Theory}

\subsection{Potential Mechanisms Through Which the Causal Ef- fect Operates}

What are the channels through which CSG receipt could affect labour market outcomes? It may change a mother's participation decision, or the number of hours she works. The latter is less likely as most workers most likely do not have this flexibility. The grant may also be used to fund or enable job search - through payment of daycare or transport expenses. The grant amount is not large, but could fund some portion of these expenses. Thirdly, the grant may raise an individual's reservation wage, resulting in fewer job offers being accepted.

\subsection{Static Model of Labour Supply}

The first possibility can possibly be illuminated if we consider the standard static model of labour supply (Blundell \& MaCurdy 1999), with an individual who maximises utility $U(y, l)$ over income $y$ and leisure $l$, with nonwage related income $G$, with the standard assumptions regarding the shape of the utility curve and it's first and second derivatives ${ }^{2}$. The individual works for $h$ hours, for wage $w$, and has total time allocation $T$. The following constraint of time: $h+l=T$, and income: $y=w h+G$, apply. Maximimising utility with respect to these constraints results in the well known tangency condition, that a solution occurs when wage $w$ equates to the marginal rate of substitution between leisure and income $\frac{M U_{l}}{M U_{y}}$.

This solution can occur at an interior point, and the individual will choose to work some non zero number of hours, or at a corner solution, where the individual is satisfied with non wage income $G$, which includes the grant, and does not work at all. The corner solution is more likely if $w$ is low, or $G$ is high. The child support grant is not large in comparison to the old age pension, and the disability and foster grants.

\footnotetext{
${ }^{2} U_{1}$ and $U_{2}>0$, both $U_{11}$ and $U_{22}<0$.
} 
Whether an individual starts from a corner or interior solution, it is the shape of the indifference curves which dictates the final position when $G$ increases upon receipt of the child support grant. An increase in $G$ shifts the budget curve outwards, and is regarded as a pure income effect. We totally differentiate our expression for utility, $U(w h+G, T-h)$, in order to establish the sign of $\frac{d h}{d G}$. The result $^{3}$ tells us that whether or not $G$ raises $h$ depends on whether or not leisure is a normal good - the familiar income effect result. This is generally assumed in the literature but cannot be taken for granted in the South African context, and in particular not amongst this group of women, given their documented high levels of unemployment. If leisure is a normal good, then a rise in $G$ is associated with a fall in labour supply, $h$. Similarly, an increase in the wage $w$, will imply a fall in $h$, due to the income effect, if leisure is normal. The reverse predictions apply if leisure is an inferior good.

\subsection{Including Fixed Costs of Working}

Our hypothesis is that the grant helps in some way to alleviate the costs associated either with job search or working. A fixed monthly cost is introduced, for instance transport cost $(T C)$, and a cost associated with each hour of working, for child care $(C C)$, if the child is below school age. Individuals maximise utility $U(y, l)$, and decide how many hours of labour to supply. We have the following situation:

$$
\begin{array}{r}
y=G \text { if } h=0 \\
y=(w-C C) h+G-T C \text { if } h>0
\end{array}
$$

It is not preferable for a woman to work if her net wage $w-C C$ is negative, no matter how high $G$ is, or how low $T C$ is. For those earning minimum wage, without free or very cheap childcare, we may see an increase in $G$, from a child becoming eligible, not resulting in any change in labour supply, or participation. Once the woman's youngest child is school going age, the cost of child care $C C$ is greatly reduced, or is zero, and whether the woman works or not is mainly dependent on the size of $T C$ in relation to $\mathrm{G}$.

$T C$ enters the equation the same way that $G$ does, and thus $\frac{d h}{d G}$ will depend again on whether leisure is a normal good. We can immediately say that if $T C>G$ then we will not see a change in labour force participation among these women. In certain groups, where the cost of working is high, for example in rural areas, the grant may not affect labour market status. In particular, if the grant is shared, we can expect it to have very little effect. However, in some groups which already have higher $G$, such as those living in a household with a pensioner, or with other higher income, we might expect to see the grant affecting participation. We will also not expect to see moves from zero $h$ to small values of $h$, because of the presence of fixed costs.

\subsection{Long Term Effects}

Should the grant affect long term employment prospects? Mothers of children aged 6 in 2002 would expect to lose the grant in the next year, and may have been surprised by the change in age cutoff which was announced for 2003. Mothers

\footnotetext{
${ }^{3}$ See derivation in the appendix
} 
with children aged 10 in 2005 have received the grant for many years, and would expect to receive it for more. Duration of receipt may be an important factor to consider when evaluating the grant effect. If we make use of the step pattern in receipt to aid in identification, it will be instructive to consider whether or not the grant is seen as a transitory or permanent shock to income levels. This implies the need to apply a more dynamic and long term approach to the problem.

If an individual receives the grant for only a short period of time, and this is known in advance, then we may expect them not to react to this shock (Heckman \& Macurdy 1980). However if an individual enters into receipt, which is expected to continue for many years, we could expect to see no response to this more permanent change, if labour supply behaves as consumption does in the lifetime model. As Heckman \& Macurdy (1980) states, it is very difficult to determine the exact definition of permanent wages/income in the labour supply model, and thus it may be hard to draw exact conclusions when thinking of this model in this way.

It is possible to turn to many and varied models of behaviour and labour supply decision making to solve this problem, such as unitary and non-unitary models, job search models, and simple extensions to the static model of labour supply. Given that $46 \%$ of the sample is married, a family labour supply model may be helpful. Later we discuss our results and interpret them using the interpretations mentioned above. In our estimations, we focus on the effect of the grant, on the participation decision, and the probability of being employed or unemployed, as we expect to see more movement in these variables than in hours of labour supply. The theory discussed helps to interpret our results, but does not determine the exact functional form of the empirical model used.

\section{Data}

Our intent was to make use of survey data which included information on actual grant receipt, and allowed us to link data from children to their mothers. Use was made of the October Household Survey (OHS) data in 1997 and 1998, and the General Household Survey (GHS), from 2002 to 2008. Both are nationally representative annual surveys. The OHS is weighted to the 1996 Census, and collected data in 3000 enumeration areas (EAs), which totalled 30,000 households. It collects data on development indicators, and labour force outcomes, such as unemployment.

The GHS is a multi stage stratified sample, which collects data in 3000 primary sampling units or EAs, having stratified by province, and type of area (rural or urban) (General Household Survey Report, 2002). The GHS master sample is drawn from the 1996 Census data. The use of the GHS and OHS data together is a good fit, as the OHS was stopped after 1999, due to financial constraints, and the GHS was introduced in 2002 to meet the subsequent need which was felt for a survey which collected data on the effect of government programs, and the level of development country wide. Access to services and facilities, and measures of education and health, were to be recorded.

The OHS data contained full birth histories, and the GHS recorded the mother's person code, thus allowing us to make the link between mothers and children. The OHS data were used in order to provide us with two pre-years 
which could be used as comparison data, before the grant was introduced universally. OHS data does exist for 1999, however a full birth history was not provided in this year, rather only for the past 12 months which was not suitable for the purposes of this paper. Unfortunately the GHS only began to be collected in 2002, and data on individual grant receipt (as opposed to household) were only collected from GHS 2003. Other nationally representative data sets include the Labour Force Survey, collected from 2000, however without any record of grant receipt.

A stacked data set of all the available years from 1997 to 2008 is built, which includes: Age, race, sex, province, education, labour force status, whether the person has an age eligible child or not, household size, number of children in the household, marital status, CSG receipt, household income, weights.

\subsection{Samples and Terminology}

We make use of the terms used in the randomised experimental literature to aid in understanding. Depending on the sample, when estimating the effect of child support grant receipt on mothers, we refer to the group who report receipt, or report having an age eligible child, as the treatment group. Depending on the sample, those who do not report receipt, or have children older than the cut-off, are referred to as the control group. Depending on the sample used, the control groups created are more or less appropriate for comparison.

A number of samples are used in the analysis. We introduce diminutive names for these samples, which shall be used from here on. The initial sample consists of black mothers between the age of 20 and 45, who have at least one child (referred to as the mothers sample, or the full sample). We then consider the sample of mothers who have an eligible child (eligible mothers), and the sample of mothers whose youngest child is aged within a year of the eligibility cut-off (the plus minus 1 sample), or within 2 years (the plus minus 2 sample). An example of the plus minus 1 sample in 2002 would be a mother whose youngest child is aged either 6 or 7 , as the age cut-off in 2002 was 7 . The plus minus 2 sample in 2002 would include mothers whose youngest children were aged 5, 6 (treated), 7 or 8 (control). Reference is also made to the sample of mothers who have any child aged within a year or 2 years of the age eligibility cut-off, but no special term is attached to these women. We also make use of the sample of mothers who are in the bottom 50 percentiles of household income - this sample is referred to as the low income sample.

Data exists for mothers aged between 15 and 49, however it was decided to use mothers aged 20 to 45 only. The teen mothers may be very different to those mothers aged 20 or above, and similarly mothers aged 45 to 49 may be at a different stage of life, and may not be likely to have a youngest child eligible for the grant. These suspicions are confirmed later when we check the balancing across the treated and control groups in this sample, and find it to be imperfect.

Table 1 shows the sample sizes of the various groups considered for analysis, and their distribution over the years. The 1998 OHS sample is smaller than that of 1997, due to budget cuts which occurred in 1998 however sample characteristic means are similar across 1997 and 1998 (table A10). The plus minus 1 sample is large enough for our purposes, although over the years the sample size naturally decreases, from 1,380 in 1997 (using the 2002 definition of the plus minus 1 sample) to 387 in 2008. This decrease is due to the departure of children other 
than the youngest child from the household as the age eligibility cut-off increases. We make primary use of the plus minus 2 sample, primarily to ensure the power of our estimates is not compromised, and for other reasons which are detailed below.

Seminar participants suggested using the sample of women whose eldest child is or is not eligible. We considered the use of this sample for a short period. The sample size of this group does not decrease over the cohorts, due to the different family structure of these mothers - they have families with fairly young children if their eldest child is near the eligibility cutoff in age.

Tables 1 through 6 were estimated using the eldest sample. Firstly, those whose eldest child was above the cut-off age, may still have been receiving the grant for a younger child. Thus those who were meant to form part of the control group may in fact be treated. Secondly, the younger children of these women were far more likely to affect their labour force participation status, as before school starts, these children need childcare, otherwise the mother cannot work. Initial balancing for this sample confirmed these suspicions, with the eligible mothers in this group being significantly younger than the ineligible mothers, less likely to be married, more likely to live in larger households, in particular houses with more children aged under 7 . These mothers were also less likely to be broad labour force participants. Given these initial balancing results, we were hesitant to trust any results with this sample, but estimated the levels for them in any case. We found that the placebo regressions did not come out insignificant, and rather showed that all that was being picked up here was an age effect in this group. Similarly the DID estimates from table 5, replicated for this sample, yielded similar results in the placebo. This line of enquiry was then abandoned.

\subsection{Data Comparability}

It is difficult to link children with their mothers. We can only work with resident children. We use two different techniques because of differences in data gathering methods - OHS uses birth histories in 1997, 1998, and GHS records the mother's pcode.

Table A2 documents the results of the two methods used to generate data for mothers. The reason for checking the efficacy and similarity of both methods is that the 1997 and 1998 October Household Surveys link mothers and children through a full birth history of resident children. In the 2002 General Household Survey both a full birth history is taken, and the mother's person code is recorded, if she is resident. For the years 2003 to 2008, the General Household Survey data only contains the mother's pcode, and no birth history is taken. Thus we can only use the one approach prior to 2000, and the other from 2003 onwards.

Luckily the 2002 General Household Survey contains both kinds of data, and we are able to do a methodology check. The data is used to create the variables needed for each mother, such as the number of children she has, the ages of her youngest and eldest children, whether or not her children are age eligible for the grant in that year. When beginning with the birth history data, the method used is to proceed with the resident children mentioned in the birth history, and collate these variables for the mothers based only on these children. When beginning with the mother pcode route, one considers only resident mothers. 
There is a concern that these methods will yield different results, but in the sample in question, of black mothers aged between 20 and 45, the means of the variables gathered using these techniques are very similar, as are the sample sizes. Significance tests (not shown) reveal some significant differences, but the actual size of the differences is very small. Using the birth history method, we count 2,347 women in the plus minus 2 sample in 2002, and 2,381 in the mother pcode sample. The average household income for the birth history full sample is R1,683.8 per month, and R1,685.6 for the mother pcode sample. Similarly, the percentage of these mothers who have an age eligible child is $65.6 \%$ in the birth history, and $65.4 \%$ in the mother pcode sample. The number of black mothers identified by the birth history is 9,569 , and by the mother pcode, 9,725 .

\subsection{Estimation Issues}

\subsubsection{Means Test vs. Controlling for Household Income}

Eligibility for the Child Support Grant is made up of two components - age eligibility, and income eligibility. The child in question must be under the age limit of that year. In 2002, the age limit was 7, thus children aged from birth to just under 7 years were age eligible to obtain the grant. A means test is then administered, which takes the income of the caregiver into consideration. On April 1st, 2002, the grant amount was R130 per month, (see table A11), and the child received this amount if the caregiver's income was below R1100 in rural areas, and R800 in urban areas. The decision was taken not to use the actual means test to determine eligibility, as traditionally household income data is very messy, and may be inaccurate. We choose to control for household income instead, which also implies we do not limit our sample size unnecessarily.Household income is a good proxy for the caregiver's income, but it is not accurate enough to use to determine those who are exactly eligible for the grant in both respects. Similarly age data may be slightly mis-measured, which is why we focus on the plus minus 2 sample for most of the analysis.

\subsubsection{Correlation}

It is likely that correlation exists between observations in each PSU, and that this correlation persists over time. To correct, we cluster by PSU. The standard errors increase only marginally, and do not change the significance of the results (see table A9, where table 2 and 3 are partially replicated.). For simplicity, and due to the lack of cluster variable in 1998, we elect to report the un-clustered estimates.

Another form of worrying clustering is group level clustering due to the research design. Possible differences across province in allocation/takeup of grants could confound our results. As each province is in charge of its own roll-out strategy, this could be problematic if individuals in each province year cell contained strong correlation. In table A5 it is possible to see both the distribution of age eligibility, and household grant receipt, by year and province. Given the construction of the sample, we expect to see these distributions shifting over time, given the changes in the age eligibility cut-off which occurred in many years. However, we can see patterns over the years which do have the same eligibility cut-off. For instance, over 1997, 1998, and 2002, where the same 
cut-off of age 7 is used to calculate eligibility (2002) and as if eligibility (1997, 1998), we can see similar static patterns of age eligibility across the provinces, which is comforting. For instance, in the Free State in 1997, 63\% of mothers have an age eligible child, while the corresponding figures for 1998 and 2002 are $64 \%$ and $61 \%$. For Gauteng across 2005 to 2008, the numbers range from 87 to $89 \%$ with no apparent pattern.

High household CSG receipt in table A5 corresponds to higher proportions of age eligible children in a logical pattern. For instance in 2004, eligible mothers are $76 \%$ in Gauteng, and $85 \%$ in Limpopo. Similarly household CSG receipt is $36 \%$ in Gauteng, and $64 \%$ in Limpopo.

A possible solution is to estimate our results using BRL standard errors which correct for any group level clustering. If the significance pattern doesn't change, then we should have no cause to worry. This seems extreme though given the lack of evidence of group level clustering in the provinces.

When using nationally representative survey data as has been done here, there is a debate as to whether to make use of weights in the estimations or not. Weights are not used here, as the sample used is not representative of the population. However un-weighted and weighted estimates do not differ significantly ${ }^{4}$.

\subsection{Heterogeneity in Treatment Effects}

In each year that is considered, the effect of the CSG is identified by a slightly different group of mothers, because of the frequent changes in cutoff age which occurred. In 2002, we estimate the effect for mothers whose children are about to enter school, and for whom many have not actually obtained the grant, as takeup was low initially. In 2003, we estimate the effect for women who did not receive the grant the previous year, and may not have applied for it in 2003, as they may have expected to lose it the following year. Given the administrative burden of application, many women may not have bothered if the expectation was to receive the grant for only one year. Once the age limit changed to 14 , again we can expect takeup rates to be low for 13 year olds, as these children will lose the grant in the next year, and thus only eager mothers could be expected to apply for the grant. In 2008 in comparison, 13 year olds could have received the grant since 2003.

We can conclude two things from the above discussion. First is that despite the slightly less perfect balancing, reporting the plus minus 2 results may be more convincing. Second, using a wide range of techniques and samples would be beneficial, as the effect of the child support grant is far from homogenous across the distribution of mothers.

\section{The South African Labour Market}

\subsection{Sample Means}

In table A10 we see the changing patterns in sample characteristics over the years, for a sample of black women aged between 20 and 45. The average age in this sample is nearly 33 in 1997, and remains constant over the years. From

\footnotetext{
${ }^{4}$ Unweighted estimates are available from the authors on demand.
} 
1997 to 2008 , mean years of education rises from 8.5 in 1997 to 9.3 in 2008 . The percentage of women who are married falls from $49 \%$ in 1997 to $44 \%$ in 2008 . Household size declines from 6.4 to 5.8 individuals, and the number of children per woman correspondingly declines from 2.6 to 2.1. Household income rises from R1,282 a month, to R2,948.

From 1997 to 2002, there is a large change in the percentage of women who are labour force participants, according to the broad definition (including discouraged workers), from $65 \%$ in 1997 to $82 \%$ in 2001 . There is a corresponding rise in employment, from $28 \%$ to $35 \%$ in 2002 , which remains fairly constant through to 2008. Broad unemployment, conditional on labour force participation, does not change dramatically in this group, ranging between 56 and $60 \%$ over the years.

\subsection{Patterns}

As seen in figure 3, there has been a large positive jump in the outcomes in question from 1997 to 2008. We graph employment, unemployment, conditional on participation (strict and broad), and labour force participation (strict and broad, which is to say strict, and including discouraged workers). Given the historically high numbers of discouraged workers, especially among black women, we consider both strict and broad unemployment. All figures shown make use of the full sample to calculate these rates - black mothers aged between 20 and 45 , with at least one child. In this group, the rates of unemployment are not particularly high. In 1997, just over $28 \%$ of this sample were employed, and $65 \%$ define themselves as willing and able to work, despite possibly not having taken steps to look for work (broad labour force participants). Approximately $43 \%$ have actually taken steps to look for work, or are working. Of those who do choose to participate, $56 \%$ are broadly unemployed, while $34 \%$ are unemployed according to the strict definition.

By 2008, there has been a marked positive shift in the economy and the labour force in particular. Employment has shifted up by 6\%, broad labour force participation by $12 \%$, and strict by $15 \%$. However, commensurate with this increase in the number of participants, we see an increase in strict unemployment of $7 \%$, to $41 \%$. Broad unemployment has fluctuated in the time period in question, eventually settling to similar levels to those seen in 1997.

We estimate a simple model ${ }^{5}$ to predict these labour force outcomes, in order to graph predicted employment, unemployment and so on, over the same time period. These predicted values follow similar patterns over time to the calculated mean values - see figure 4 .

In figure 5, each labour force outcome is plotted against the age of the woman's youngest child, in order to ascertain how, on average, woman's labour force status changes as their children grow up. We use pooled data over all the years. We can see that woman with younger children, below the age of 3 , have very low employment probability, of under $20 \%$. This rises in a fairly linear fashion with the age of the youngest child, reaching approximately $50 \%$ when the child is aged 15. There are similar patterns to broad and strict labour force participation, while unemployment correspondingly falls from a high of $53 \%$

\footnotetext{
${ }^{5}$ The model controls for whether the woman has an eligible child, province fixed effects, household size, number of children, the woman's age and years of education, whether she is married or not, and a measure for household income.
} 
(strict definition), to a low of approximately $25 \%$, for a youngest child aged 15 . Having the child enter school at age 7 or thereabouts seems to push employment up by a fair percentage. We need to be careful when evaluating the effect of the child support grant when the age limit is 7 , as the effect measured may be due to the child entering school, and not the grant. These jumps in the graphed outcomes are even larger for the predicted outcomes (figure 6).

Similar to the previous exercise, we again predict labour market outcomes, for each group of women. For instance, we calculate predicted employment, for the women whose youngest child is aged 0 . Then for those whose youngest child is aged 1, and so on. These figures are graphed against the age of the youngest child - see figure 16. These calculations are performed in each year, allowing us to see how the patterns in each outcome change over the years, and over the age distribution. In figure 7 , we can see the pattern in broad labour force participation, which does not appear to have changed dramatically over the years. Mother's labour force participation rises as her youngest child grows up.

We are now interested to see whether there are any clear patterns or discontinuities in the data which arise around the age cut-off. It is difficult to know for certain, as the data appear to be fairly volatile. We must remember that in certain years, changes which occur slightly before the age cut-off could possibly be attributed to the grant, if grant receipt begins to fall before the cut-off, for reasons detailed above. In the years 2003 to 2005, it seems we should look at changes slightly before the cut-off, as in each of these years, grant receipt falls precipitiously before the age limit. In 2006, 2007 and 2008, we can confine our attention to the area immediately after the cut-off. 2002 is also a good year to look exactly at the cut-off, as for many years before this, there had been no changes in the age eligibility rules. However, 2002 had an age limit of 7 , which is school going age, so may not be a good year for discussion, as it is hard to separate out the effects of receipt, and school attendance, on mother's labour force status. What is strange is that in 2002 of all the years, we would expect to see a large discontinuity at age 7 , and we do not. It is possible that not all children enter school exactly at age 7 however.

In the years 2002 to 2005, broad labour force participation falls slightly before the age cut-off (figure 7). This pattern is seen in the predicted outcome graph too - figure 8. For the years 2005 to 2008, when the age cut-off was 14 , it appears that mothers either reduce or keep their labour force participation stable, once their child loses the grant.

Strict labour force participation falls before the cut-off in the years 2003, 2004 and 2005, and either remains constant or falls after the cut-off in the years 2006 to 2008 (figures 9 and 10). This effect appears weak but constant over all the years. Predicted strict labour force participation seems to follow a similar pattern.

Broad unemployment falls before the cut-off in 2003-2005, and after the cutoff, in 2002, and 2006 to 2008 (figures 11 and 12). This might accord with mothers entering the labour force after the child becomes ineligible, and looking for jobs, but not finding them. Predicted broad unemployment does not display a fixed pattern, rising in some years, and falling in others around the cut-off.

Strict unemployment falls before the cut-off in the years 2002 to 2005, and after the cut-off in the years 2006 to 2008 (figures 13 and 14). However there is a general downward trend over the age distribution, and it may be that we pick up 
an age effect, and not the effect of grant receipt. Without further investigation, this is not conclusive evidence. Predicted strict unemployment falls before the cut-off in 2002-2005, but appears to rise after the cut-off after 2007.

Employment seems to fall before the cut-off in 2003, 2004, and 2005. In 2006 and 2008, employment rises after the age cut-off (figures 15 and 16). In 2002, we seem to see the effect of children becoming of school going age at age 7 , as employment rises around this point. Predicted employment is highly variable, and no firm patterns can be seen.

In summary, broad and strict unemployment appear to fall around the cutoff. If there is a pattern to labour force participation (broad and strict), it is weak, but it seems it might fall around the cut-off. Employment does not seem to show a firm pattern of change around the cut-off. It may be the case that when the grant is lost, mothers look for jobs (as unemployment falls). However it may be that this is due to mothers exiting the labour force, as we see a corresponding fall in labour force participation after the cut-off. Thus the grant could be helping mothers to remain in the labour force, and eventually, but not immediately obtain jobs. To see an immediate change in employment would be quite startling, given the small size of the grant. When these figures are replicated for a low income sample ${ }^{6}$ more likely to be affected by grant receipt, we see sharper patterns, similar to those discussed above ${ }^{7}$. We also see a sharp fall in employment around the cut-off, which may imply that losing the grant makes working unprofitable, without the grant to fund travel and child care. This is speculation however - and given the overall variability in these graphed outcomes, it may be a bit of a stretch to make this connection.

These graphs show us that if anything a fuzzy regression discontinuity design would be appropriate, and certainly not a sharp one. Due to the relatively small size of the grant, it is reasonable that it would not impact too sharply on labour market status by itself, and indeed, it does not seem to. The graphed outcomes are also fairly variable, and thus it is hard to ascribe the jumps we see as due to the grant alone. However this does not imply we are not still interested in the effect of the grant on labour market outcomes, rather that we consider it in conjunction with other factors, and that we approach the problem of identification from a number of different angles, including but not limited to the regression discontinuity approach.

In our actual estimates of the effect of eligibility, or receipt, on labour market status, we might expect to see eligibility associated with higher unemployment (compared to ineligible mothers), slightly increased or no change in labour force participation, and either no change or higher employment for eligible mothers in low income households. Our estimates will measure the effect of grant receipt, which is lost when mothers' children become ineligible. We now turn to the full estimates.

\subsection{Patterns in Receipt}

In figure 1, we plot child support grant receipt, against the age of the youngest child, in each year. Each graph shows the age cut-off in red. Sadly we only have data on individual receipt from 2003, as the 2002 GHS only records household

\footnotetext{
${ }^{6}$ The bottom 50 percentiles of the household income distribution - figures 17 to 28 .

${ }^{7}$ These figures are available in the appendix.
} 
grant receipt. A mother is defined as receiving the grant, if either her child is recorded as receiving the grant (the majority of cases), or if she reports grant receipt. In the full sample, of those whose youngest child is aged 1 , in 2003, approximately $24 \%$ report receiving the grant. It seems to take mothers some time to establish grant receipt after their child is born, although this initial figure climbs over time, from $16 \%$ to over $40 \%$ by 2008 . This shows the improved shared knowledge in communities about how to apply for a grant, and fewer delays once the application has been received.

In each year that the age limit has changed, it appears to take time for the knowledge to filter down to recipients and beneficiaries. For instance, the limit changed from 7 to 9 in 2003. Very few mothers of 7 and 8 year olds report receiving the grant in 2003 however. It is possible that those who do receive the grant are simply the group which would naturally have fallen out of the system, had the age limit not changed, but automatically continue to receive the grant. Given these patterns, it seems likely that mothers who could apply to receive the grant for one year only choose not to, due to the high administrative cost, and the shortened period of receipt, as they may take some time to hear their child is once again eligible. If the application process was also arduous when they first applied for their child, or if their child was unlucky enough to always just miss receiving the grant, they may not have high incentives to apply.

In the years in which the age limit does not change, or has not just changed, there is a much sharper cutoff in receipt - for instance in 2006, 2007 and particularly 2008. This implies using a regression discontinuity design may be more fitting in these years than others. In 2003 to 2005, the bandwidth would have to be rather large, and a fuzzy design with IV estimates would seem to be indicated. In table A4 we report individual grant receipt for actual children, rather than their mothers. These means correspond to those seen for the mothers in figure 1 .

When making use of a regression discontinuity design, it is important to check that the running variable, in our case, age of the youngest child, has not been manipulated in order to gain access into the program. If this were the case, we would expect to see bunching in the age distribution immediately before the age cut-off. In figure 2, the numbers of children in our sample receiving the grant are plotted for each year. There does not appear to bunching in the age distribution, although this doesn't rule out the possibility that mothers may lie to the Department for Social Development regarding the age of their children, although this would require some level of sophistication. It seems unlikely that ages are being manipulated on a scale large enough to interfere with our results, especially since beneficiaries begin to receive the grant years prior to the cut-off, and it would be impossible for mothers to predict the changes in age limits in future years.

In table A2 we investigate the change in grant receipt over the years ${ }^{8}$. No data were recorded in GHS 2002 for individual grant receipt. In 2003, 38\% of all black mothers report living in a household which receives at least one CSG, compared to $46 \%$ of mothers with at least one eligible child. Our plus minus 1 and 2 samples report living in 15 and $19 \%$ of households receiving the grant, implying there is variability in this variable in our samples of interest. However for individual grant receipt in the same year, the figures are lower. $31 \%$ of all

\footnotetext{
${ }^{8}$ These means are unweighted, however weighted means do not differ significantly.
} 
black mothers report receipt (either directly or through their child reporting receipt), compared to $42 \%$ of mothers with an eligible child. In the plus minus 1 and 2 samples, the corresponding figures are 6 and 11\%, implying some but not very much variability in receipt in these samples. Receipt increases however, and by 2008 , the corresponding figures for the plus minus 1 and 2 samples are 31 and $35 \%$. For household grant receipt, the figures are 45 and $48 \%$.

\section{Identification}

\subsection{Strategy}

A simple regression of employment status on CSG receipt, or age eligibility, conditioned on household income, may not eliminate endogeneity. CSG receipt is correlated with many factors, such as wealth, health, educational status, and other variables which may be unobserved. The coefficient on receipt may reflect the effect of these other correlated variables, and not the true effect of receipt itself.

The first strategy used is to make use of a sample suggested by the regression discontinuity literature, in order to limit the sample to those in which receipt may be considered random. This is combined with a second strategy to include controls which attempt to reduce the endogeneity observed in receipt, such as mother's age, education levels, marital status, location, household size, and others.

The third strategy used is to attempt to make use of information available in the years pre-treatment, or pre grant rollout, and to use a difference in differences estimation. The difference in differences estimation, if all the assumptions are met, cleans out both year and group effects, leaving us with the true effect of receipt on labour market outcomes. A fourth technique is attempted, which is a modified difference in difference, across consecutive years, where the pattern of age eligibility allows us to identify valid treatment and control groups. Finally, a fifth strategy is used, to presume a fuzzy regression discontinuity design might be appropriate, given the pattern in grant take-up, and to instrument for grant receipt with age eligibility, while controlling for household income.

\subsection{Level Specification}

We estimate a levels specification, in each year $t$ separately, where an observation $i$ represents an individual.

$$
Y_{i t}=\alpha_{0}+\alpha_{1} X_{i t}+\beta \text { Treat }_{i}+\theta Z_{h}+\gamma W_{p}+u_{i t}
$$

Where $Y_{i t}$ represents one of the three outcomes of interest that we focus on, namely broad labour force participation, unemployment conditional on participation, and employment ${ }^{9} X_{i t}$ is a vector of individual level characteristics including number of children, age, years of education and a marital status binary variable. Treat $_{i} t$ is the treatment variable under discussion, whether that

\footnotetext{
${ }^{9}$ All estimates are performed including in addition strict labour force participation, and strict unemployment conditional on participation. However these results do not differ substantially from their broad counterparts, thus we decide not to report them. Estimates available from the authors on request.
} 
is individual grant receipt, or having one's youngest child be age eligible. $Z_{h}$ is a vector of household level characteristics, including household income and size. $u_{i t}$ is an idiosyncratic error. $W_{p}$ are province fixed effects. In the pooled sample, year fixed effects are included ${ }^{10} . \beta$ is the coefficient of interest.

In table 2 we estimate equation (3) using individual grant receipt as the treatment variable. These estimates are performed separately in the plus minus 2 sample, and the full sample. Despite including a variety of controls, it is possible that we do not adequately eliminate the omitted variable bias associated with grant receipt. Nonetheless we must start from this base, to see how these results differ from future better specifications. In the full sample, receipt is correlated with higher labour force participation, of between 2 and $3 \%$ over the years, and in the pooled sample. This effect is significant at the $5 \%$ level in most years. Similar size coefficients are seen in the plus minus 2 sample, but they are not significant.

We see higher unemployment associated with receipt, in the full sample, and this figure increases over the years, from $6 \%$ in 2003 to $15 \%$ in 2008 , with $13 \%$ in the pooled sample. Similar trends are seen in the plus minus 2 sample, although the effect only becomes significant from 2006, and ranges between 7 and 10\%, with $8 \%$ in the pooled. This makes sense given our knowledge of grant receipt in the plus minus 2 sample - the sharp cut-off in receipt is only really seen from the year 2006 onwards. The effect on employment is negative in the full sample, ranging from 4 to $11 \%$, and it grows over time. These coefficients have high levels of significance. However in the plus minus 2 sample, no significant effect is really found, except in the pooled sample, of minus $5 \%$, not as high as in the full. It could be that omitted variable bias is lower in the plus minus 2 sample, and thus the effect of receipt is closer to the true estimate. We do expect the omitted variable bias to be negative, as all the omitted variables are expected to have a negative effect on the outcomes (CHECK THIS)

In table 3, we estimate equation (3) using a treatment variable of whether the mother's youngest child is age eligible for the grant or not, and we control for household income ${ }^{11}$. We do this firstly to check whether age eligibility is a good proxy for grant receipt, as if it is this in part justifies its use as an instrument for receipt, and it justifies our using age eligibility as our main variable of interest, if the two variables measure the same effect on our outcomes under discussion. We can also examine whether or not age eligibility as a proxy for receipt simply measures an age effect, and if so whether or not we can isolate the effect of receipt through eligibility by using the plus minus 2 sample.

We also estimate the effect of eligibility in 1997 and 1998, using the 2003 definition of eligibility, in order to ascertain whether or not we estimate a simple age effect - that of having a younger child ${ }^{12}$. In the full sample, the effect on labour force participation is similar to that of receipt, and slightly larger, ranging between 2 and 5\% from 2004 to 2008. In the two pre-treatment years, 1997 and

\footnotetext{
${ }^{10}$ For individual grant receipt, we pool the years from 2003 to 2008 . For eligibility, we pool the years 2005 to 2008 , where the age eligibility cut-off is the same, to ensure we are measuring the same effect. Seminar participants have recommended allowing the pooled eligibility sample to include all the years from 2002 to 2008 - doing this makes no difference to the results.

${ }^{11}$ Creating a variable for whether or not the mother passes the means test is messy, and not necessarily correct given that we may not have all the sources of income recorded in the data. We elect not to do this.

${ }^{12}$ We decide not to use the 2002 definition, as this is too closely tied to the effect of having one's youngest child enter school.
} 
1998, we see that we are indeed measuring the effect of having a younger child, in the full sample, as these coefficients are significant, for the most part. In the plus minus 2 sample however, these placebo estimates do not yield significant coefficients in 4 of the 6 estimates, but in 2 they do ${ }^{13}$.

The effect of eligibility on unemployment is also similar in direction and significance to receipt, although these estimates are smaller. The eligibility coefficient for unemployment ranges from 4 to $9 \%$ in the full sample. However in the plus minus 2 sample there is only one significant coefficient, that of $9 \%$ in 2008. Eligibility is associated with reduced employment of between 3 and $7 \%$ over the years in the full sample, but again in the plus minus 2 sample, we see only one significant coefficient, that of $-7 \%$ in 2008 .

We presume that in the plus minus 2 sample we are closer to reducing the omitted variable bias associated with grant receipt, or age eligibility. It seems the negative effect of grant receipt on labour market status is all but eliminated when we reduce OVB, by using age eligibility. However we are not left with much else which is significant. Both tables 2 and 3 are estimated for white women, a group which shows very low levels of CSG receipt. For table 3, this shows the simple age effect of having a younger child, which is seen to have indeterminate and inconsistent effects on participation and unemployment, and to raise employment in some cases. For table 2, the estimates are not significant.

We now move onto the differences in differences estimates, which make use of extra information in the pre-treatment years to aid our understanding.

\subsection{Difference in Difference}

A difference in differences estimator involves pooling data across pre and post treatment years, and making use of time and group dummies to net out these effects, leaving the true effect of treatment in the post year. The first assumption is that our defined treatment and control groups are similar in characteristics prior to treatment beginning in the post year. In case they are not however, we include controls for the observed characteristics for which we have data. These controls should be netted out by the inclusion of the time and group dummies, but they aid in increasing the precision of the estimates. The second assumption is that the composition of the groups does not change from the pre year to the post year, an assumption which is checked when we examine the age distribution of youngest children, and find it does not change over the age eligibility cut-off.

However should our treatment and control groups not be similar in the pre treatment year, this would cast doubt on the assumption of similar trends in both groups, prior to treatment. Thus before we estimate the coefficient in question, we run balancing tests to ensure that our assumption of similar means are correct. The specification for the balancing tests is as follows:

$$
X_{i t}=\alpha+\beta \text { Treat }_{i}+\mu_{i t}
$$

Where $X_{i t}$ refers to any one of the observed characteristics of age, years of education, marital status, household size and number of children, household income, and pre-treatment labour market outcomes. This specification

\footnotetext{
${ }^{13}$ In estimates using the plus minus 1 sample, the placebo estimates are all insignificant. However there is a tradeoff between statistical power, and balanced coefficients across the age cut-off. We choose to focus on the plus minus 2 sample to increase the power of our treatment variable estimates, due to the nature of the grant receipt pattern over the years.
} 
is estimated for the pre-years, pooled and separately, for a number of different samples. We choose to report the results of the 1997 balancing tests, due to space constraints. The other estimates do not differ significantly. We also ran specifications in which we included province dummies, as the proportion of eligible children may differ by province - these estimates do not differ in significance. We choose to report the simple specification instead, as this allows us to report $\alpha$, which is the mean value of the characteristic in question, for the control group (those who have Treat ${ }_{i}$ equal to zero). If the assumption of equal characteristics across the groups is correct, we should expect to see the coefficient on Treat $_{i}$ emerge as insignificant.

In table A3, the results of specification (4) are shown in 3 different samples - the full sample, and the plus minus 1 and 2 samples (youngest child is aged either 1 or 2 years close to the cut-off). In the full sample, we see that the mean value for the control group for age is 38 years. Treated individuals (those whose youngest child is age eligible, using the 2003 definition $^{14}$ ) have a mean age which is lower by 6.71 years, and this difference is significant (the $\mathrm{T}$ statistic is 55.46). This makes sense, as mothers with eligible children are bound to be younger than those whose children are not age eligible.

Similarly, we see other significant differences which have been reported in the literature. Mothers of eligible children have 0.88 more years of education (possibly due to their lower age, and the improved education available when they went to school), are no less likely to be married, live in households which are larger (the difference is 0.84 children), have 0.51 more children on average, have lower household income of 202 rand, have unemployment probability which is 17 percentage ppoints higher, are less likely to be in the labour force (10 percent), and are less likely to be employed (16 percent). These results confirm our earlier suspicion that eligible mothers are different to the rest of the general population, and the specification estimated in tables 2 and 3 may be flawed.

Columns (1) and (2) convince us that using the full sample may not be indicated in the difference in difference estimator. When we turn to the plus minus 1 and 2 samples, in columns (3) to (6), we see that these differences mostly fall away. Eligible mothers in these two samples do not differ in their labour market status in the pre-treatment years, nor in marital status, household size, and years of education. They do still differ in age, which is reasonable, and household income in the plus minus 1 sample. However in the plus minus 2 sample, this difference is not significant. Thus we choose to use the plus minus 2 sample for the difference in difference estimator, as it is both large enough to afford us enough statistical power, and it is balanced across the characteristics in question. We do control for mother's age in the specification.

We perform more extensive balancing tests for the plus minus 2 sample, across the 4 age cut-offs, in table A8. Again we see that age is always significantly lower for eligible mothers. Household size is significant for the test across the 2004 age limit, as are labour force participation and employment. Thus mothers whose youngest child is younger than 11 in 1997 are less likely to be labour force participants, or employed. There is no institutional or structural connection to this specific age which gives us cause for concern, but these results do convince us to pay attention to the 2004 results.

\footnotetext{
${ }^{14}$ We run the balancing tests using the 2002 definition of age eligibility, age 7 , but decide not to report them. They reveal similar patterns to 2003, but we felt the significance of 7 as the school going age meant our results might be mis-interpreted.
} 
The difference in difference estimator is obtained from the following specification, using a regression in a pooled dataset over the years in question.

$$
Y_{i t}=\alpha_{0}+\alpha_{1} X_{i t}+\gamma \text { Post }_{t}+\beta \text { Treat }_{i}+\text { sPost }_{t} \text { Treat }_{i}+\theta Z_{h}+\gamma W_{p}+\mu_{i t}
$$

Where $Y_{i t}, X_{i t}, Z_{h}$, and $W_{p}$ are defined as in the levels specification. Now however Treat ${ }_{i}$ refers only to age eligibility of the youngest child. Post $_{t}$ is a binary variable for whether an observation originated in the pre-years of 1997 and 1998, before the grant was introduced, or in the post years we consider, of 2002 to 2008. $\delta$ is our coefficient of interest, as it represents the effect of age eligibility (our proxy for grant receipt, when we control for household income), cleaned of the effects of both time, and group effects related to having an age eligible and therefore being the mother of a younger child.

We estimate equation (5) in different stacked data sets, in table 4. We pool the pre-years 1997 and 1998, with each post year separately, as each of 2002, 2003, 2004 and 2005 have a different age limit. We also then pool the pre years with 2005 to 2008 , as the age limit remained 14 in each of these years. Year dummies are included.

Using a DID estimator, we can remove the effect of time on CSG receipt, and the effect of differences between eligible and ineligible households, or mothers. The key assumption is of similar trends pre treatment in each group, which would have continued on a similar path had treatment not occurred. In general, difference in difference estimators are performed on pre and post years which are close together in time, lest other shocks disturb the assumption of similar trends. In our case, thanks to the nature of the data available, and the pattern of receipt, which only builds to significant levels from 2002, we do not have much choice in the matter of which years to use. However we do realise this means some of our estimates may be capturing any other large structural change in these years. We do not build completely on these results, but use them to inform us further.

The estimates in table 4 appear to show that the levels may not have appropriately dealt with the endogeneity of receipt or age eligibility. We estimate equation (5) using the plus minus 2 sample, and then the low income sample. Having an age eligible child raises the probability of being a labour force participant by between 5 and $10 \%$ in the plus minus 2 sample, and between 9 and $12 \%$ in the bottom 50 sample. The probability of being employed does not change significantly in the plus minus 2 sample, but falls in the low income sample by between 9 and $13 \%$. Broad unemployment, conditional on participation, is higher for eligible mothers by between 7 and $12 \%$, but these effects are only significant in the 2007 and 2008 pooled samples. In the low income sample, unemployment rises by between 15 and $22 \%$, and these effects are significant from 2005 onwards.

In order to test that we do not measure a simple age effect, we estimate placebo specifications, using 1997 as the pre year, and 1998 as the post year, with equation (5). If we are simply estimating an age effect, we would expect these coefficients to emerge as significant, however they do not. Similarly, we estimate table 4 using the corresponding group of white mothers, aged 20 to 45 . No significant effects are found. These estimates are available from the author on request.

We now move onto the fourth strategy, that of the modified difference in differences. 


\subsection{Modified Differences in Differences}

In table 5 , we take advantage of the pattern of change in the age eligibility cutoff which creates natural comparison groups. For instance, between 2002 and 2003, the age limit changed from 7 to 9 . We make use of the sample of mothers of 7 to 10 year olds, in both years. In 2002, no child in this group receives the child support grant, while in 2003, the 7 and 8 year olds are eligible to receive the grant. We estimate equation (5), with Treat $_{i}$ defined as being the mother of a 7 or 8 year old, control defined as the mother of a 9 or 10 year old, and the Post $_{t}$ year defined as 2003. The interaction between Treat $i$ and Post $_{t}$ yields the coefficient of interest - the effect of grant receipt, net of year and group effects. Once again, control variables are included in order to increase the precision of the results. There is no specific reason to suggest why mothers of 8 or 9 year olds should differ, especially if we have controlled for the age of the mother. Another advantage to this method is that now observations are compared very closely in time, which reduces the possibility that some other trend or shock is confounding our results.

Before we plunge into these estimations, we once again run balancing tests, using equation (4), to check the critical assumption of equal characteristics across treatment and control groups. Previously these balancing tests were run for 1997, now we run them in each year from 2002 to 2008, across each age limit. The results are presented in table A7, for the plus minus 2 sample. Once again for the ease of reporting, province fixed effects are omitted, although the results do not differ significantly if they are included.

In 2002, we see in table A7 that mothers whose youngest child is eligible are on average 1.63 years younger than ineligible mothers, and this difference is significant (the $\mathrm{T}$ statistic is -6.22 ). This age difference is significant across all the years, although it is particularly large in 2002. Similarly, number of children is larger for eligible mothers, although this difference is not large. The majority of the balancing tests do not reveal significant differences, which supports our use of the difference in difference estimation in table 5 .

In 2002 however, due to the age cut-off value of 7, we do see significant differences, as this is school going age. Mothers with an eligible child in 2002 are on average $7 \%$ more likely to be unemployed, $3 \%$ less likely to be in the labour force, and $7 \%$ less likely to be employed. These pre-treatment significant differences tell us we should be wary of the results for 2002, but we are confident with the other years.

Table 5 measures something slightly different to the estimates in table 4 , as previously we were estimating the effect of eligibility for two groups, where one of the groups lost eligibility, from the pre year to the post year. Here one of the groups gains eligibility from the pre year to the post year. Together with the close proximity of the years, we may be identifying a more precise version of the eligibility effect. Again controls are included to improve precision and control for any differences not netted out by the time and group fixed effects. A pooled sample of the years 2002 to 2008 is also used in column (4), where we compare the mothers of those aged 11 to 14 to those aged 14 and 15, with the pre years being defined as 2002 to 2004 .

We see that age eligibility is associated with no significant change in labour force participation in each of the separate year difference in difference estimates, however the pooled sample shows an increase of $4 \%$, and $5 \%$ in the low income 
sample. Broad unemployment conditional on participation falls by between 6 and $8 \%$ in 2003 and 2004 in the plus minus 2 sample. Employment rises by between 6 and $8 \%$, but no significant coefficient is seen in the pooled sample, or in the low income sample. These estimates are very different to those in tables 2,3 and 4.

Placebo regressions are also estimated in the years 2005 to 2006,2006 to 2007, 2005 to 2008, using an artificial age limit cut-off of 10. These coefficients should not be significant, and indeed they are not. Column 2 of table 5 is replicated for many different groups, to establish the robustness and origin of this result. The results are presented in table 6 . To a lesser or greater extent, the effects are very robust and fairly similar across the different groups.

Women who are in the top 50 percentiles of the household income distribution are affected more strongly by grant receipt, with an increase in average employment probability of $11 \%$, and a fall in unemployment, conditional on participation, of $11 \%$. The grant effect is slightly smaller for those with a matric compared to those who do not have a matric ${ }^{15}$, with those lacking a matric seeing unemployment fall by $10 \%$ on beginning receipt.

Married woman are very slightly more affected by the grant, similar to those in the top 50 percentiles of the income distribution. Those who live in a household with a pensioner have a stronger effect due to grant receipt. Women who are in their 20s see the largest effect due to grant receipt - an increase in employment probability of $15 \%$, and a fall in unemployment, conditional on participation of $14 \%$, and very large increase in labour force participation of $9 \%$. The effects decrease with age. White women do not see any effect due to grant receipt.

We now move on to the instrumental variables estimates, which are motivated by use of a fuzzy regression discontinuity design.

\subsection{Regression Discontinuity}

It is possible to make use of the allocation design of the child support grant to aid us in our estimation of the effects in question. Around the age eligibility cutoff, we expect to see a sharp discontinuity in receipt. In table A4, the distribution of individual grant receipt is shown, by age and year. The cutoff line is highlighted in black. It is possible to see the sharp decrease in receipt in every year, following the cutoff line. In some years, such as 2003 or 2004, receipt is not high in the age group just before the age eligibility cutoff. This could be due to mothers who do not bother to reapply for the grant when their child is going to lose it the next year, or is expected to lose it, if the announcement of the new cutoff is delayed. Another possible problem is measurement error in the age variable, and those reporting low receipt in the age year group before the cutoff, are actually ineligible for the grant.

It seems given the patterns seen in table A4 that a sharp or possibly fuzzy regression discontinuity design might be indicated. As in our previous specifications, we do not have access to a valid counterfactual - we cannot observe what mothers' outcomes would have been had their children not received the grant, for those with eligible children. We assume that treatment is essentially

\footnotetext{
${ }^{15}$ Matriculation status is achieved on completing 12 years of education, and passing the Department of Education examinations, which are written nation wide.
} 
endogenous - many factors are correlated with child support grant receipt, such as household income, education levels, health status, and others. Thus even when controlling for as many observables as we reasonably have data for, we expect our estimate of the effect of treatment to be flawed.

Assignment to grant receipt, conditional on passing the means test, is a deterministic function of the age of the child, as follows:

$$
C S G=1\left[\text { Age }<A g e^{*}\right]
$$

We know that the probability of being treated changes sharply at $A g e^{*}$, however other characteristics such as household income, education, etc should not change dramatically around this point. The balancing tests in tables A3, A7 and A8, have established that this is the case, both in the pre-year of 1997, and across the years 2002 to 2008 .

For the sharp RD, we feel comfortable restricting our sample to a small bandwidth around $A g e^{*}$, and then simply regressing our outcome on the treatment, as was done in the level estimates in tables 2 and 3. If we assume some fuzziness in the design, i.e. that some individuals who are aged above the cutoff still obtain receipt, and those who are eligible do not all obtain receipt, then it may be appropriate to instrument for treatment with age eligibility. If we move to a fuzzy $\mathrm{RD}$, we more closely approximate the IV results estimated in table (IV).

This assumes we can only estimate the average treatment effect at $A g e^{*}$, one particular point in the age distribution of children, by comparing the mean of the outcome variable immediately to the left and the right of $A g e^{*}$. The assumption is that the only difference in outcomes between those who are treated and those who are not, on either side of the cutoff point, is due to the treatment itself, and nothing else. It may be that this effect is not very similar to the effect of the treatment for the entire population. Mothers who have children aged 6 in 2002 may be very different to those with children aged 2 or 3 - thus it is possible that we cannot generalise our results.

A possible check is to graph employment outcomes from the previous year on age of the child in this year, in each district (the smallest geographical unit which is repeatedly sampled). Employment in 2002 should be very important in determining employment in 2003, but should not be seen to have a discontinuity around the age eligibility cutoff in 2003. If we do see a discontinuity, we have reason to worry that some other factor is driving our results.

It is important to know that our choice of bandwidth does not drive our results. We would expect to see the results more imprecisely estimated, but largest in size, with the smallest possible bandwidth. As our bandwidth grows, the estimates may tend towards zero, but should increase in significance. Ideally we would like the effects estimated not to change significantly with the bandwidth. All the relevant tables have been run for the plus minus 1 sample, and similar coefficients are reported ${ }^{16}$

The granularity of our data is potentially a problem. We cannot talk about the asymptotics of approaching the age cutoff, as we only have rounded age data. A potential robustness check, from Lee \& Card (2008) is to check that our results are not sensitive to clustering at the level of the data. If clustering does not increase the size of the standard errors, then the discreteness of the

\footnotetext{
${ }^{16}$ These estimates are available from the authors on request.
} 
data is not a problem - those observations clustered in the same age group have similar data, and it is not a problem that a few observations may be mis-assigned to the wrong group (eligible to non-eligible, or vice versa). All tables have been estimated with and without clustering, and the size of the standard errors does not change significantly.

The difference in difference estimates may not be credible if treated individuals (mothers of 6 year olds) differ significantly from mothers of 7 year olds, over time. If for instance school attendance rates jumped significantly between 1997 and 2002, our DID over the years 1997-2002 might not be appropriate. A regression discontinuity design controls for this possibility, by holding constant random variation in labour market status among treated and control individuals.

Takeup was initially slow. In 2002 , only $23 \%$ of mothers who had an eligible child, lived in a household which reported grant receipt. This figure increased to $65 \%$ in 2008 . There is variation in CSG receipt in our sample of interest black mothers whose youngest child is aged within a year of the cutoff - $35 \%$ report living in a $\mathrm{HH}$ which receives a CSG.

\subsection{Instrumental Variables}

In the plus minus 2 sample, we make use of 2SLS to estimate the effect of grant receipt on labour market outcomes. We instrument for individual grant receipt (as reported by either the mother or the child), using whether the mother has an age eligible child. We first consider whether this is a plausible instrumental variable, when used in this manner. Whether the child is 6 or 7 can be considered random in the sample of mothers with children aged 6 , or 7 . Thus if controls for the age of the mother are also included, we could possibly assume that having an age eligible child only affects the mother's labour market outcomes through its effect on grant receipt, in this sample. The IV must also predict treatment; if the child is aged six, he or she is age eligible for the grant, and may be receiving it, however rates of receipt drop sharply above the age eligibility cutoff. See for instance in table $\mathrm{A} 4$, in 2003. $2 \%$ of 9 year olds, and $1 \%$ of 10 year olds report grant receipt. These figures can be considered zero for all intents and purposes. Thus the probability of receipt is different, depending on the different values of the instrument.

Monotonicity should in theory also be satisfied, as it would be extremely unlikely for a child who was age eligible to not receive the grant, and then when age ineligible to somehow receive the grant - this is not rational behaviour on the part of the mother, and it could be expected that the number of mothers like these would be small. The probability of there being defiers in the sample is very low, due to the structure set up by the Department of Social Development - when a child hits the age cutoff, they automatically stop receiving the grant. Similarly it is difficult for a child to obtain the grant without proof of age. The estimate we obtain for the effect of the child support grant on labour market outcomes could also be conceivably fairly close to the Average Treatment Effect, as there is no good reason, having controlled for mother's age, that the group of mothers who respond to this instrument is very different to those who don't.

The specification used for the IV results is as follows:

$$
Y_{i t}=\alpha_{0}+\alpha_{1} X_{i t}+\gamma C S G_{i}+\beta T_{t}+\theta Z_{h}+\gamma W_{p}+\mu_{i t}
$$


Where $C S G_{i}$ is grant receipt, which is instrumented for by Treat $_{i}$, a binary variable for whether or not the mother's youngest child is age eligible or not. $Y_{i t}, X_{i t}, Z_{h}$, and $W_{p}$ are defined as in the levels specification. We include year fixed effects $T_{t}$ when estimating equation (7) in a pooled sample of the years 2006 to 2008 . The years 2006 to 2008 are used for the IV estimates, due to the nature of the grant receipt pattern, and the first stage results, which show the instrumental variable is weak in the years 2003 to 2005 . We do not have data on individual grant receipt in 2002. This specification is estimated in the plus minus 1 and 2 samples, and the low income sample - see table 7 .

Given the lack of data on grant receipt, the samples obtained are not large. Unfortunately, we do not obtain conclusive results using this technique. In the smallest sample (plus minus 2), the instruments are very weak in places, and thus we do not obtain significant coefficients on grant receipt. Despite that our outcomes are binary, we elect to use standard 2SLS, taking the bad with the good of the linear probability model - our coefficients are easy to interpret, and comparable, but they are not limited to the range between zero and one, and indeed they do not always stay in that range. This unfortunate phenomenon however only occurs in cases where the instrument is very weak (below 0.05). In other combinations of years and outcomes, the instrument is stronger $(0.45$ to 0.6 ), but the results obtained are mostly insignificant.

There is no significant pattern of association between grant receipt and labour force participation in any of the samples. Broad unemployment appears to increase with grant receipt, by between 15 and 32 percentage points in the plus minus 2 sample. Employment appears to fall in 2008 for those receiving the grant, but we do not see this significant coefficient in the other years. For the most part, the results are inconclusive.

Part of table 7 shows the IV estimates for the full sample, which is not entirely permissable given that the IV loses its justification as a valid IV in this sample, and rather represents the effect of having a younger child. The full sample results accord fully with the levels and DID, which is interesting as those results were obtained using the plus minus 2 sample. It is possible that having controlled for various important characteristics such as age of the mother, education, marital status, province, number of other children, and household income, it is possible that our IV is still randomly assigned in these groups, but unlikely. In the full IV sample, the effect of CSG receipt is to increase the probability of being in the broad labour force by between 7 and $15 \%$, not to affect strict labour force participation at all, and to affect employment probability negatively, by between 5 and $13 \%$. These effects are not as strong when we estimate the effect of having an age eligible child on household CSG receipt, which is sensible as we would not expect household CSG to have much effect on individual labour market outcomes, especially if resources are shared equally, or not at all.

\subsection{Mechanisms}

In table A6, we estimate equation (3) using 3 new outcome variables, in order to shed some light on the causal mechanisms through which grant receipt affects labour supply. Not many variables exist in the General Household Survey to aid in this question. We examine the number of children of school going age (7 to 15) who attend school, the number of children of below school going age 
(0 to 7 ) who attend a creche or daycare of some sort. We also examine the number of children not attending school due to lack of money for fees. In all these specifications, the number of children, and the number of children aged under 7 are included as variables on the right hand side, as well as the other usual characteristics.

We find that receiving the child support grant increases the number of children going to school, conditional on the number of children that the mother has. This effect is significant and consistently a similar size across the years. Grant receipt is associated with an increase in the number of children attending school by between 0.08 to 0.12 across the years in the plus minus 2 sample, and by 0.04 to 0.20 in the full sample. There is no change in the number of children reporting not attending school due to lack of money for fees, which is expected as this variable has a very low mean to begin with. The number of children aged under 7 attending daycare increases with receipt by between 0.3 and 0.12 , with the biggest effect seen in 2003. These effects are significant at the $1 \%$ level.

Thus we see that grant receipt could be funding daycare, and the costs associated with sending a child to school. This simple model does not account for the number of child support grants received. We have no data for transport costs associated with getting to work.

\section{Discussion}

We feel that table 5 contains not only the most robust results, but also the most econometrically correct. From table 5 and 6 we conclude that the grant has a positive effect on labour market participation and employment probability, and reduces unemployment. These effects are not small.

\subsection{Connection to the Theory}

We expected that if fixed costs of working were high, we might expect to see the grant have an impact for those in slightly higher income households, who already are some way towards funding these costs. This we see in table 6 . We also expected that changes in eligibility which were anticipated would be reacted to less substantially, if we accept a permanent income hypothesis. This we see in table 5 , where already by 2005, knowledge of the grant, and the age cut-off is growing, and the size of the effect is smaller.

Younger women respond much more to receipt of the grant, and this may again imply a lack of funds to overcome the fixed costs of working. It is possible that for this group of women in particular, either their indifference curves are very peculiarly shaped, or leisure is an inferior good. Simply put, the prediction that a rise in $G$ would lower $h$ is not seen here, or is not reflected in the participation and employment decisions.

\subsection{Other Issues}

Another concern is that the results estimated are due to some other issue which arises at the cutoff. For instance, in the year 2002, the age cutoff is 7 . Children in South Africa enter school at age 7, thus potentially freeing their mothers to enter the labour force. Thus the effect we estimate in 2002 may not be 
entirely attributable to the effect of the grant, and it may not be in the expected direction. Those with an eligible child in 2002 are being compared to those who have a school going child, and thus we might expect to see a negative effect. Similarly in 2003, where grant receipt is not high in the age groups before the cutoff, and children may enter school late, we may again be seeing the effect of having a non school going child, rather than the effect of the grant. What we do see both in table 2 and 3, is that the effects estimated in 2002 and 2003, where the age cutoffs were 7 and 9 , are mostly zero or negative, with only the coefficient in the employment status model in 2002 reported as negative and significant. Another reason why the effects seen in table 5 and 6 strengthen in size and significance over the years is that grant takeup initially rose slowly from very low levels. It is difficult to separate these two effects, that of low takeup, and school entrance.

It is important to remember that like work done with the South African Old Age Pension, the effects are identified using only resident children and mothers. We do not include the effect of CSG receipt by mothers whose children are not resident, whether those children have been sent away to family, or the mother has left the home to seek work. Thus the negative effects on labour force participation which are found in the levels estimates may be mitigated if we take into account the possible positive effect of remittances sent by working mothers.

Seminar participants suggested replicating these results but excluding household income as a control. Household income is endogenous, due to mis-measurement, and to its correlation with other unobserved factors. Replication of tables 2, 3, 4 and 5 excluding household income do not yield a significantly different estimate of the effect of the grant, or eligibility. If the coefficients do vary,the variation is very small.

\section{Conclusions}

Using a stacked data set from the OHS and GHS from 1997 to 2008, we investigate the effect of the child support grant on labour market participation, unemployment conditional on participation, and employment status, in a group of black mothers, aged 20 to 45 . We exploit the step wise pattern of receipt from 2002 to 2006 to identify the effect of the grant.

We find that grant receipt is associated with a higher probability of being the labour force, lower unemployment probability for those who do participate, and a higher probability of being employed. These effects are not small, ranging as high as $15 \%$ for some groups. There is some heterogeneity in these results, which accords with the theory of the static labour supply model, with a fixed cost associated with working.

Much further work remains to be done at this point. Thus far, no attempt has been made to exploit the variation in the number of child support grants received by each woman, nor the duration in receipt, apart from passing references. The variation in the grant amount over the years has also not been exploited in any meaningful way, and it could help to shed further light on the problem.

Another meaningful extension or check would be to see how two other important variables change in response to the grant. The first, actual weekly hours 
worked, may not be expected to change, if individuals do not have power to vary their hours, but if we saw variation in this quantity, it would be interesting. The other is earnings - if the grant enables women to be able to wait for better paying jobs, rather than taking the first available job, we would expect to see this reflected in earnings. We may also expect to possibly see a difference between changes in paid work, and unpaid work. We may find that the grant enables women to seek paid work, rather than working for the household, or tending crops or animals.

Another robustness check which is needed is to estimate equation (5) in table 5 without any controls, in order to see that the specification is not sensitive to the distribution of the unobservables across the control and treatment groups (Blundell \& MaCurdy 1999). 


\section{References}

Aguero, J. M., Carter, M. R. \& Woolard, I. (2009), The Impact of Unconditional Cash Transfers on Nutrition: The South African Child Support Grant.

Bertrand, M., Sendhil, M. \& Miller, D. (2003), 'Public Policy and Extended Families: Evidence from South Africa', World Bank Economic Review .

Blundell, R. \& MaCurdy, T. (1999), Labour Supply: A Review of Alternative Approaches, volume 3 edn, Elsevier Science, chapter 27, pp. 1558-1695.

Boler, T. (2007), Facing the Consequences of AIDS: Orphans, Educational Outcomes and Cash Grants in South Africa, PhD thesis.

Budlender, D., Burns, J. \& Woolard, I. (2007), 'Analysis of Survey Data on the Impact of Social Security Grants'.

Budlender, D., Rosa, S. \& Hall, K. (2005), 'At All Costs? Applying the Means Test for the Child Support Grant'.

Budlender, D. \& Woolard, I. (2006), 'The Impact of the South African Child Support Grant and Old Age Grants on Children's Schooling and Work'.

Case, A. \& Ardington, C. (2006), 'The Impact of Parental Death on School Outcomes: Longitudinal Evidence from South Africa.', Demography 43(3), 401-20.

URL: http://www.ncbi.nlm.nih.gov/pubmed/17051820

Case, A., Hosegood, V. \& Lund, F. (2005), 'The Reach and Impact of Child Support Grants: Evidence from KwaZulu-Natal', Development Southern Africa 22(4), 467-482.

Delany, A., Ismail, Z., Graham, L. \& Ramkissoon, Y. (2008), 'Review of the Child Support Grant; Uses, Implementation and Obstacles'.

Eyal, K. \& Keswell, M. (2008), Identifying Pure-Income Effects in an Empirical Model of Labour Supply: the Case of the South African Social Pension.

URL: http://www.saldru.uct.ac.za/papers/wpapers/2008_19.pdf

Goudge, J., Russell, S., Gilson, L., Gumede, T., Tollman, S. \& Mills, A. (2009), 'Illness-Related Impoverishment in Rural South Africa: Why does Social Protection work for Some Households but not Others?', Journal of International Development 21(January), 231-251.

Heckman, J. J. \& Macurdy, T. E. (1980), 'A Life Cycle Model of Female Labor Supply', The Review of Economic Studies Ltd. 47(1), 47-74.

Hunter, N. (2004), 'Welfare Grant Administration in KwaZulu-Natal: looking at the Child Support Grant. Research Report, 62'.

Hunter, N. \& Adato, M. (2007a), The Child Support Grant in KwaZulu-Natal: Perceptions and Experience inside the Household.

Hunter, N. \& Adato, M. (2007b), The Child Support Grant in KwaZulu-Natal: Understanding Administration and Household Access. 
Lee, D. \& Card, D. (2008), 'Regression Discontinuity Inference with Specification Error', Journal of Econometrics 142(2), 655-674.

URL: http://linkinghub.elsevier.com/retrieve/pii/S030440760700111X

Leibbrandt, M., Woolard, I., Finn, A. \& Argent, J. (2010), Trends in South African Income Distribution and Poverty since the Fall of Apartheid.

URL: http://www.oecd-ilibrary.org/oecd/content/workingpaper/5kmms0t7p $1 \mathrm{~ms}$ en

Lund, F. (2008), Changing Social Policy: The Child Support Grant in South Africa, Human Sciences Research Council, Cape Town.

URL: www.hsrcpress.ac.za

Makiwane, M., Desmond, C., Richter, L. \& Udjo, E. (2006), 'Is the Child Support Grant associated with an Increase in Teenage Fertility in South Africa? Evidence from National Surveys and Administrative data'.

Posel, D., Fairburn, J. \& Lund, F. (2006), 'Labour migration and households: a reconsideration of the effects of the social pension on labour supply in South Africa,"', Economic Modelling 23, 836-853.

URL: http://linkinghub.elsevier.com/retrieve/pii/S0264999305000970

Ranchod, V. (2006), 'The Effect of the South African Old Age Pension on Labour Supply of the Elderly', South African Journal of Economics 74(December), 725-744.

Samson, M., Heinrich, C., Williams, M., Kaniki, S., Muzondo, T., Quene, K. M. \& Van Niekerk, I. (2008), 'Quantitative Analysis of the Impact of the Child Support Grant'.

Samson, M., Lee, U., Ndlebe, A., Gandhi, V., Harigaya, T., Abrahams, C., Quene, K. M. \& Niekerk, I. V. (2004), 'The Social and Economic Impact of South Africa's Social Security System'.

URL: http://www.sarpn.org.za/documents/d0001041/index.php

Timaeus, I. M. \& Boler, T. (2007), 'Father Figures: the Progress at School of Orphans in South Africa.', AIDS (London, England) 21 Suppl 7, S83-93.

URL: http://www.ncbi.nlm.nih.gov/pubmed/18040169

Triegaardt, J. (2005), 'The Child Support Grant in South Africa: a social policy for poverty alleviation?', International Journal of Social Welfare 14, 249255.

Williams, M. J. \& Samson, M. (2007), 'The Social and Economic Impacts of South Africa's Child Support Grant'.

Woolard, I., McEwen, H. \& Kannemeyer, C. (2009), Social Assistance Grants: Analysis of the NIDS Wave 1 Dataset.

URL: $\quad$ http://www.nids.uct.ac.za/home/index.php?/NidsDocumentation/discussion-papers.html

Yamauchi, F. (2006), Early Childhood Nutrition, Schooling and Sibling Inequality in a Dynamic Context: Evidence from South Africa. 


\section{Child Support Grant Receipt}

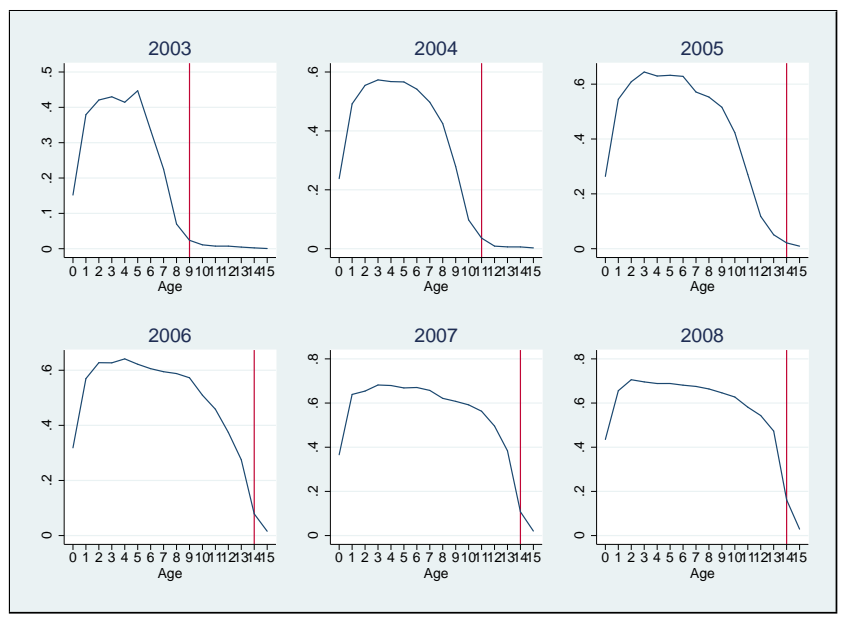

Figure 1: Child Support Grant Receipt Distributed by Age

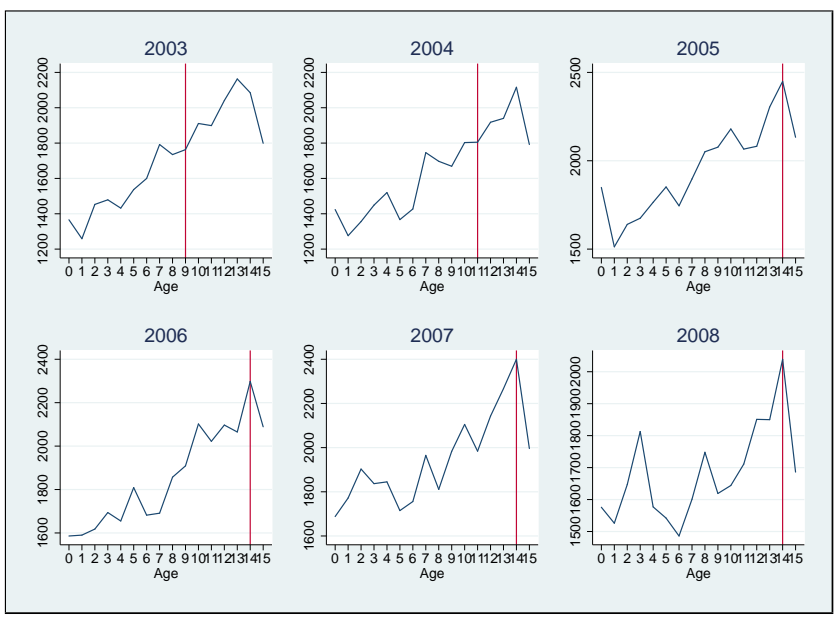

Figure 2: Age Distribution 


\section{Labour Market Outcomes Graphed Across Time}

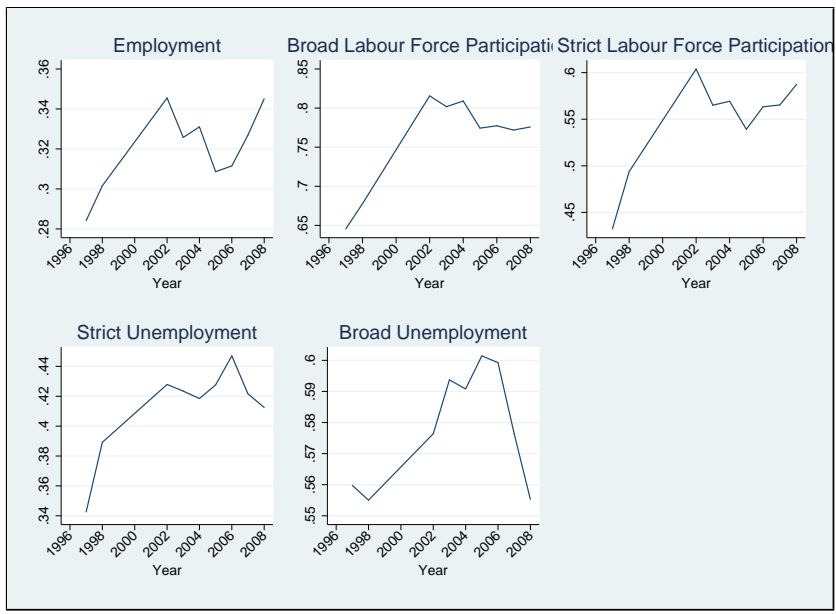

Figure 3: Outcomes Pooled Across Time

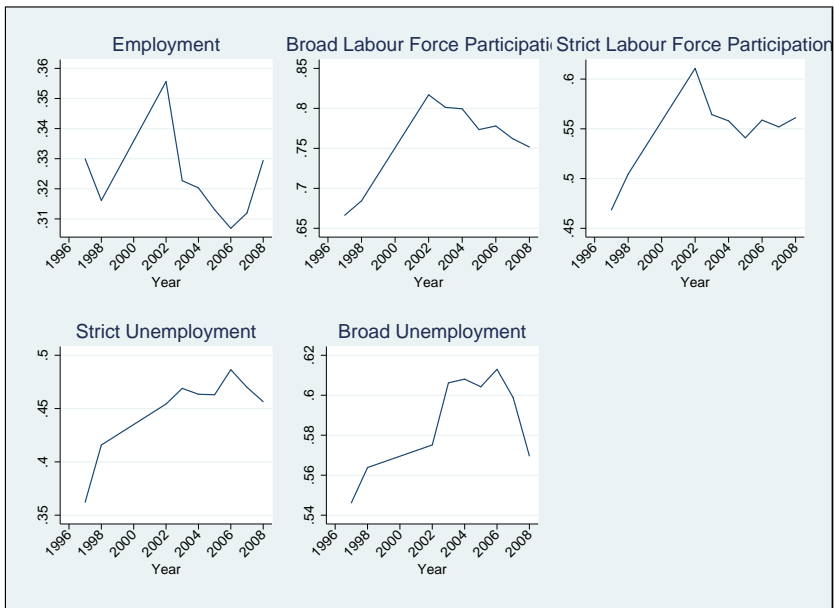

Figure 4: Predicted Outcomes Across Time 


\section{Labour Market Outcomes Graphed Across the Age of the Youngest Child}

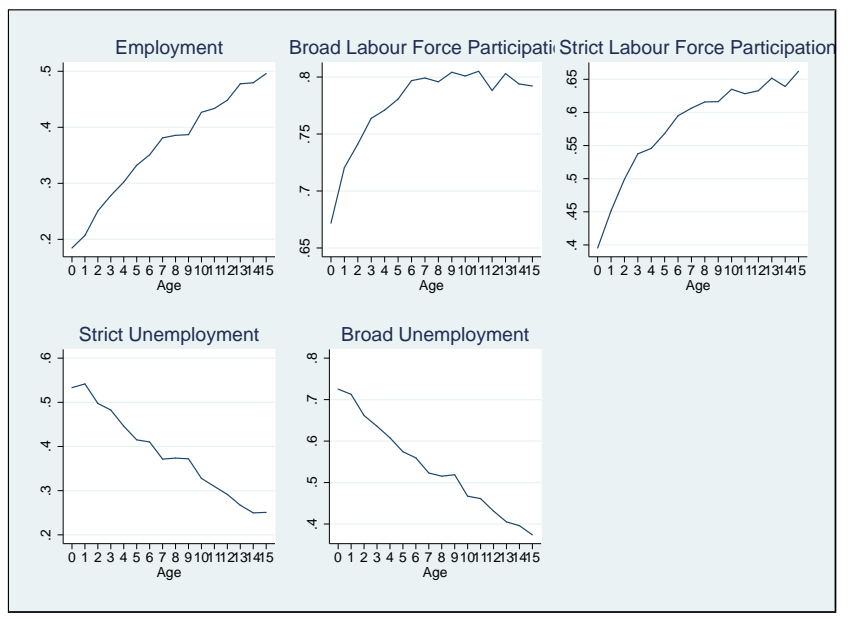

Figure 5: Outcomes Pooled Across the Age Distribution of the Youngest Child

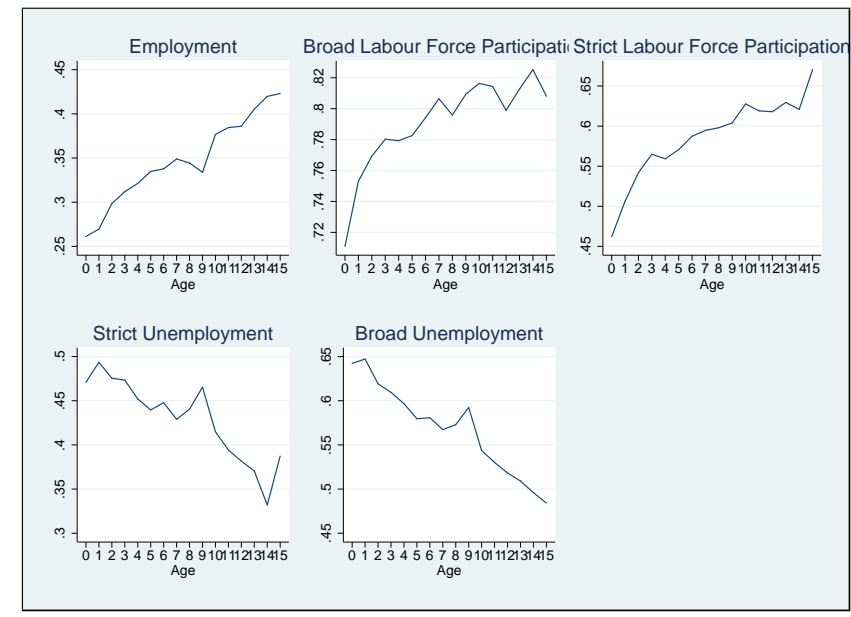

Figure 6: Predicted Outcomes Pooled Across the Age Distribution of the Youngest Child 


\section{Labour Market Outcomes: Actual and Pre- dicted}

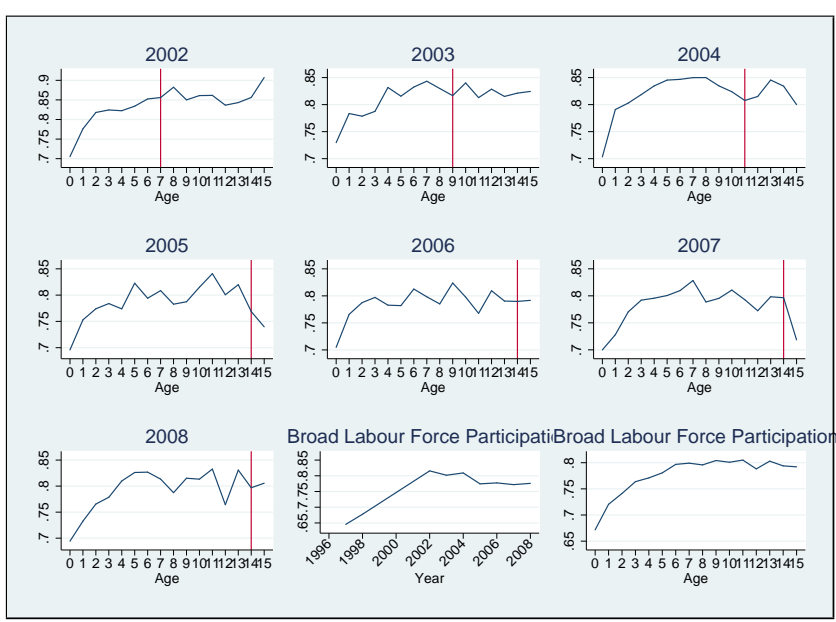

Figure 7: Broad Labour Force Participation

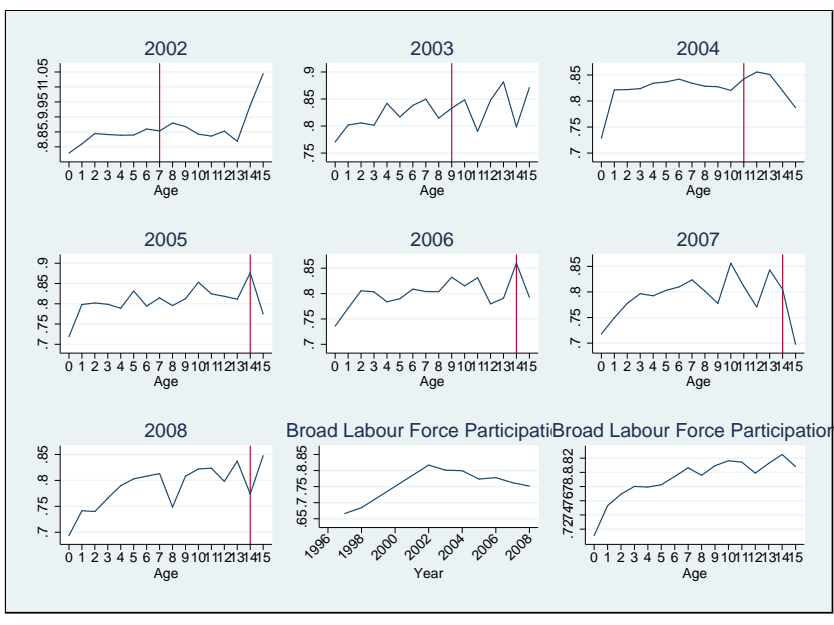

Figure 8: Broad Labour Force Participation: Predicted 


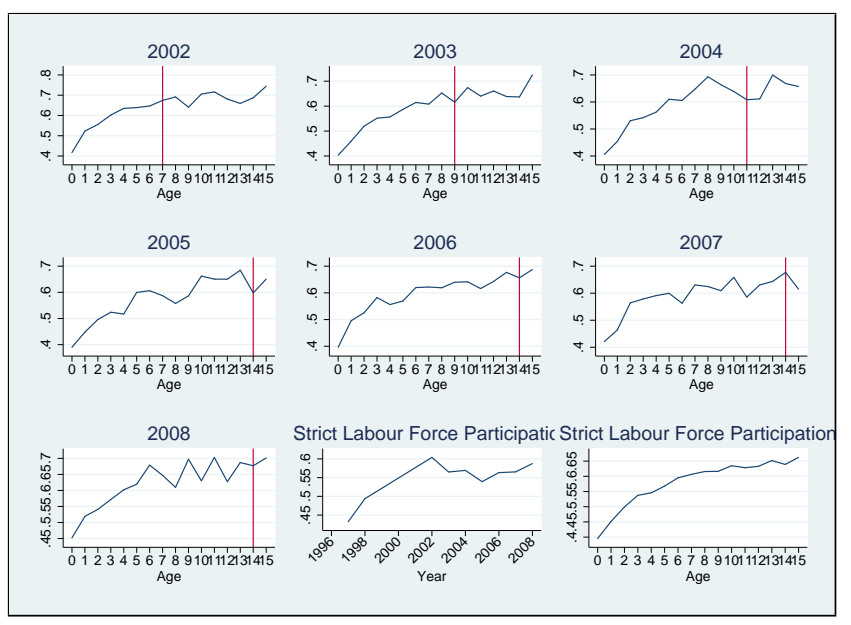

Figure 9: Strict Labour Force Participation

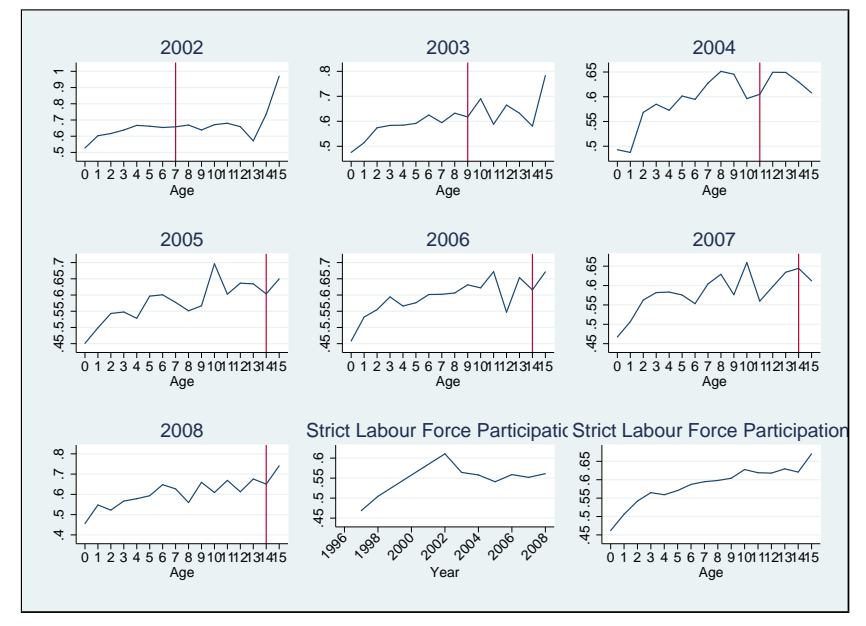

Figure 10: Strict Labour Force Participation: Predicted 


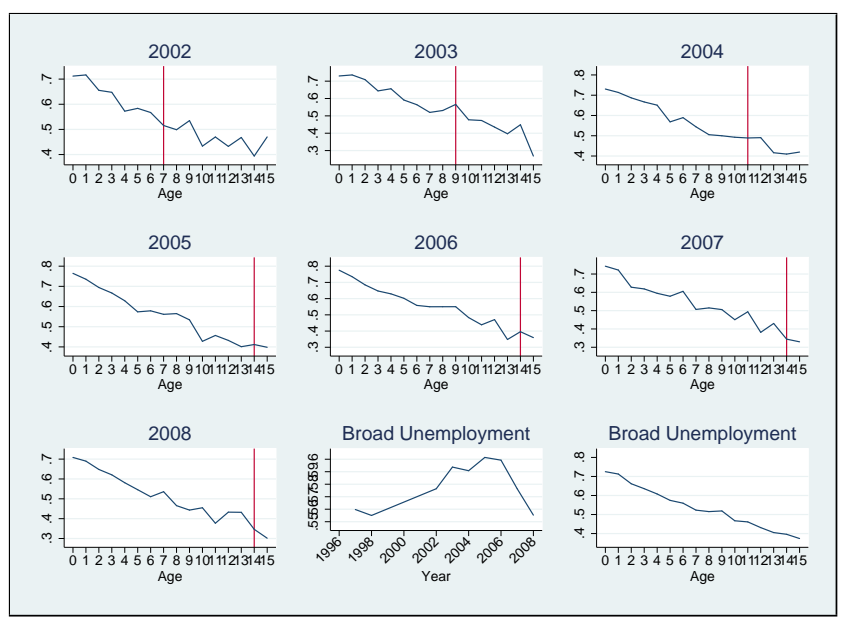

Figure 11: Broad Unemployment

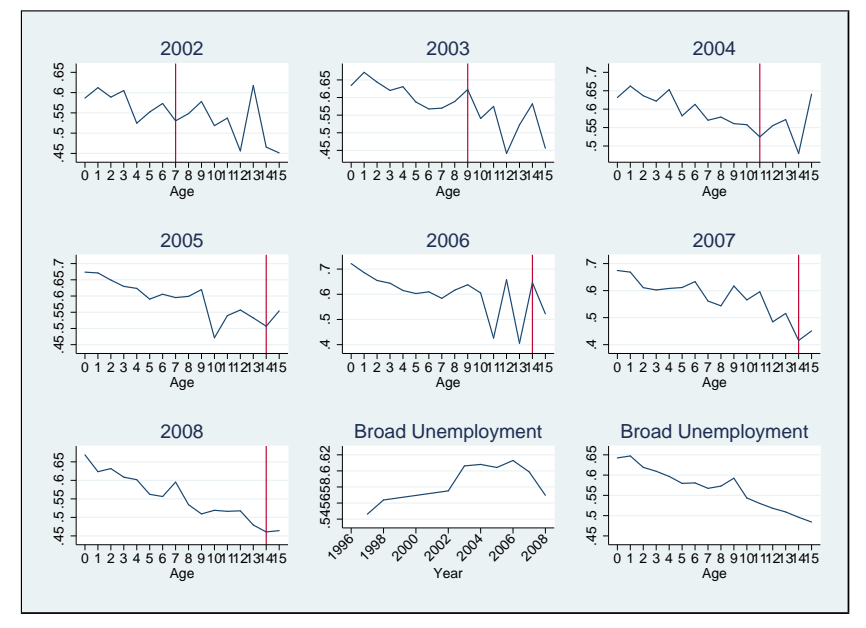

Figure 12: Broad Unemployment: Predicted 


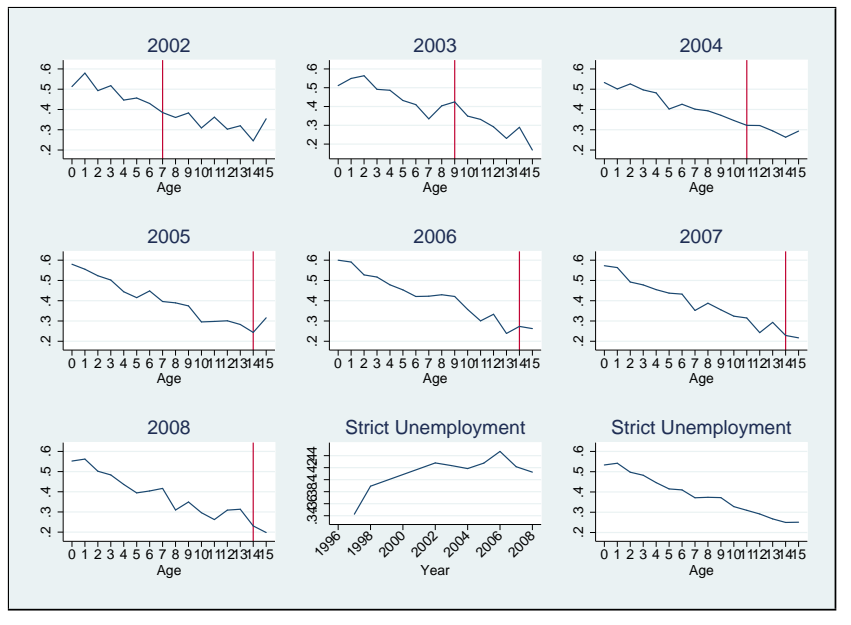

Figure 13: Strict Unemployment



Figure 14: Strict Unemployment: Predicted 


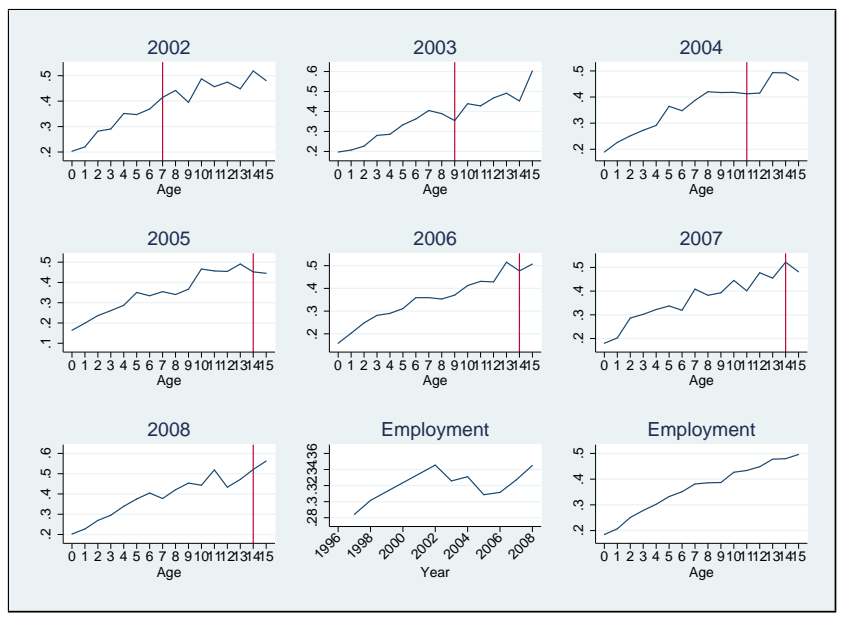

Figure 15: Employment



Figure 16: Employment: Predicted 


\section{Labour Market Outcomes: Bottom 50 Per- centiles of the Income Distribution}

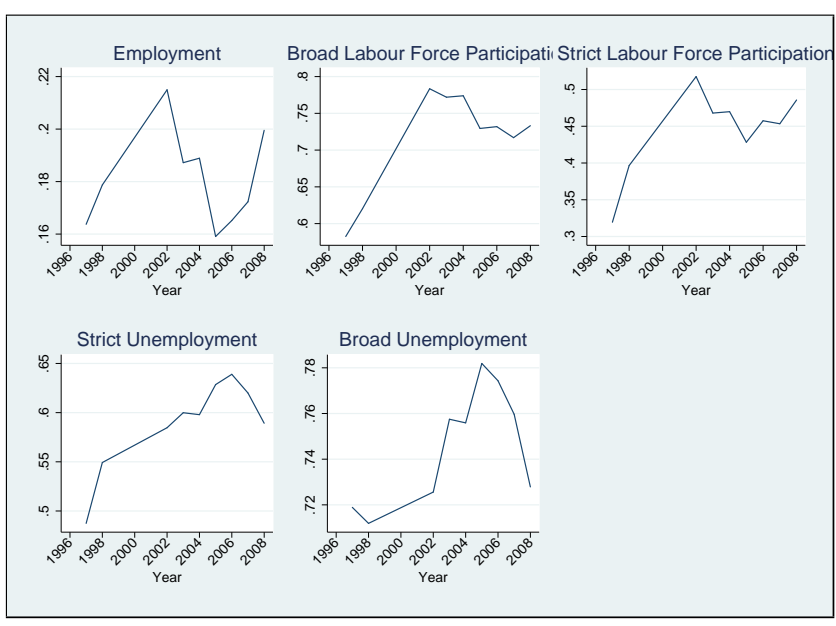

Figure 17: Outcomes Across Time: Bottom 50 Percentiles of the Distribution

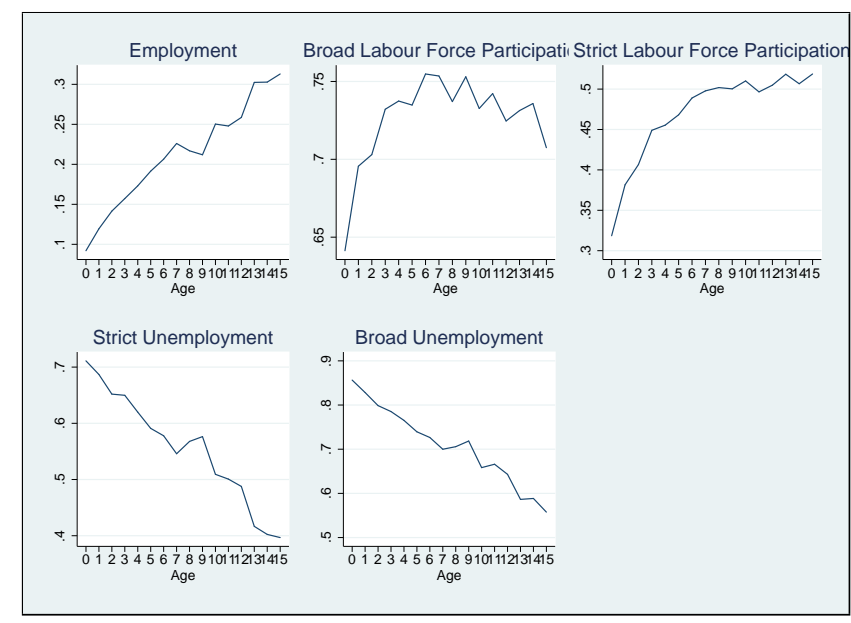

Figure 18: Outcomes Pooled Across the Age Distribution of the Youngest Child: Bottom 50 Percentiles of the Income Distribution 


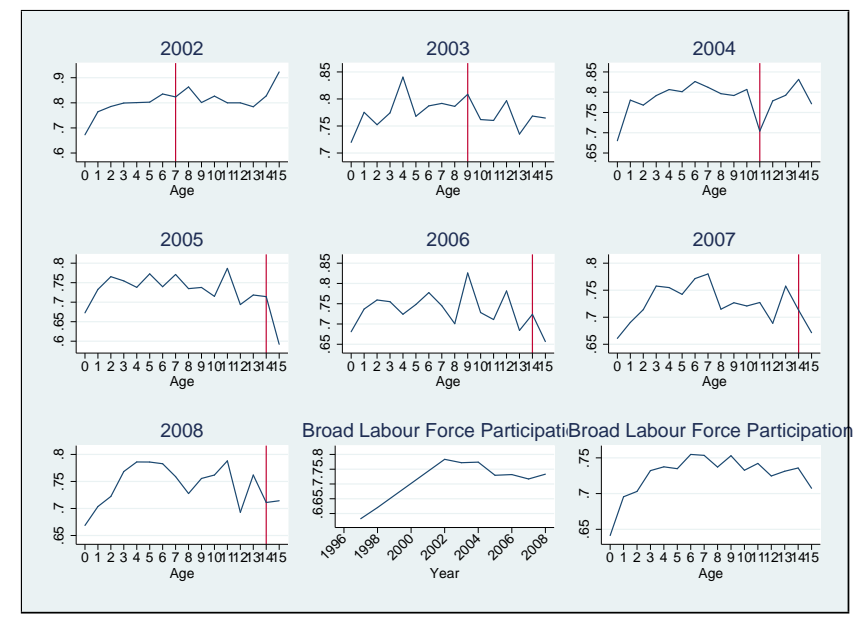

Figure 19: Broad Labour Force Participation: Bottom 50 Percentiles of the Income Distribution

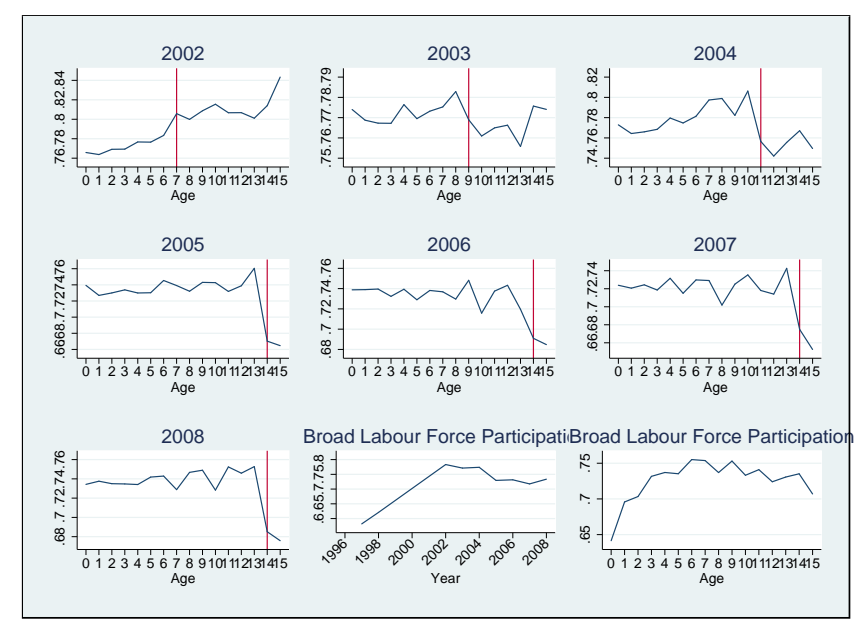

Figure 20: Broad Labour Force Participation: Predicted (Bottom 50) 


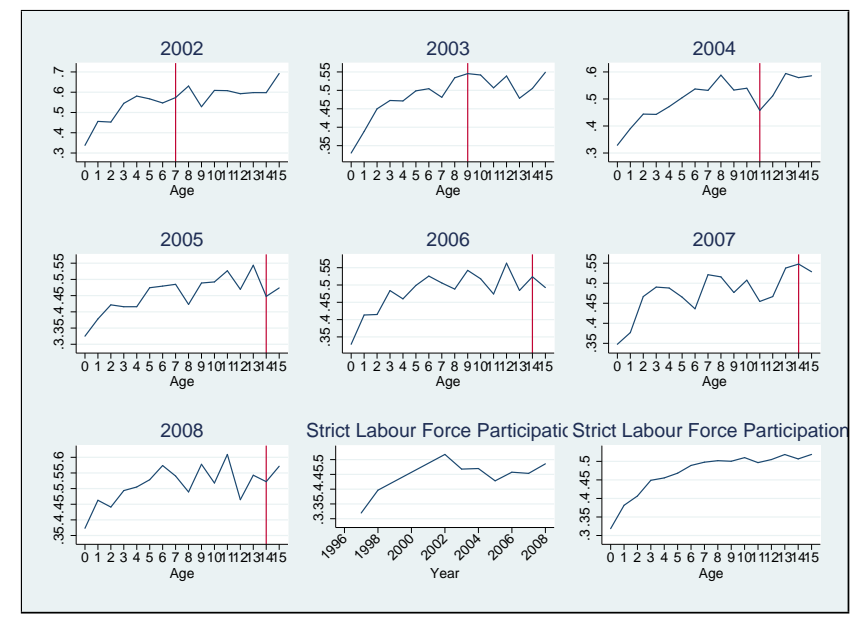

Figure 21: Strict Labour Force Participation: Bottom 50 Percentiles of the Income Distribution

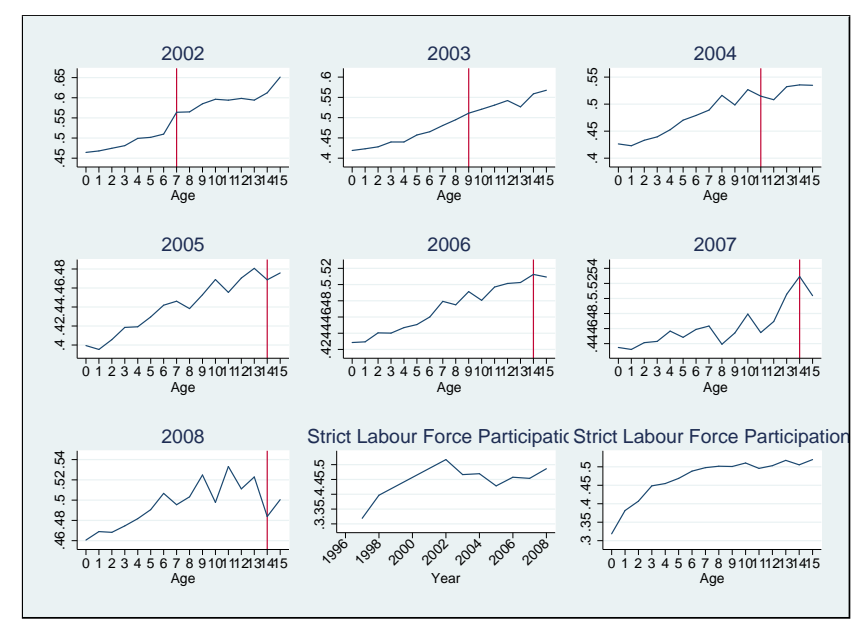

Figure 22: Strict Labour Force Participation: Predicted (Bottom 50) 




Figure 23: Broad Unemployment: Bottom 50 Percentiles of the Income Distribution

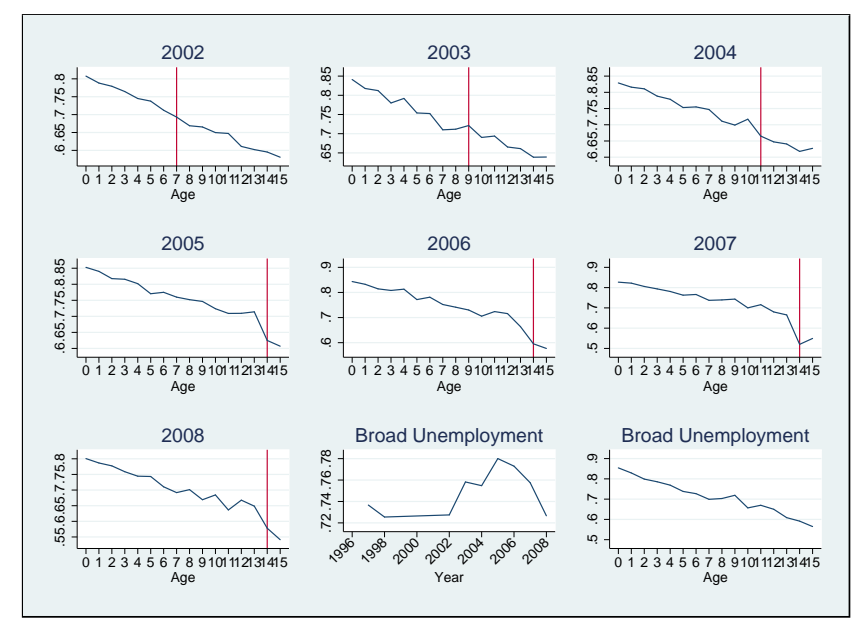

Figure 24: Broad Unemployment: Predicted (Bottom 50) 


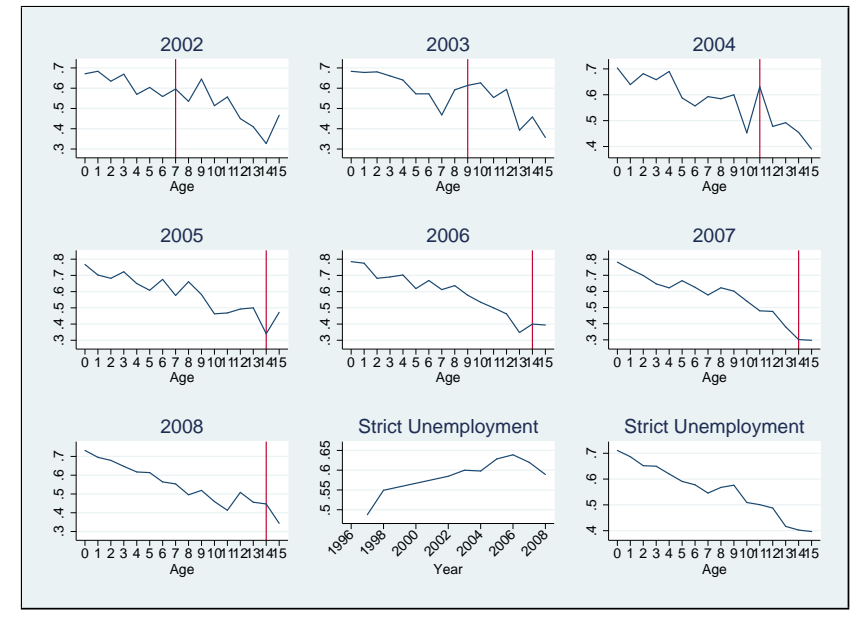

Figure 25: Strict Unemployment: Bottom 50 Percentiles of the Income Distribution



Figure 26: Strict Unemployment: Predicted (Bottom 50) 




Figure 27: Employment: Bottom 50 Percentiles of the Income Distribution

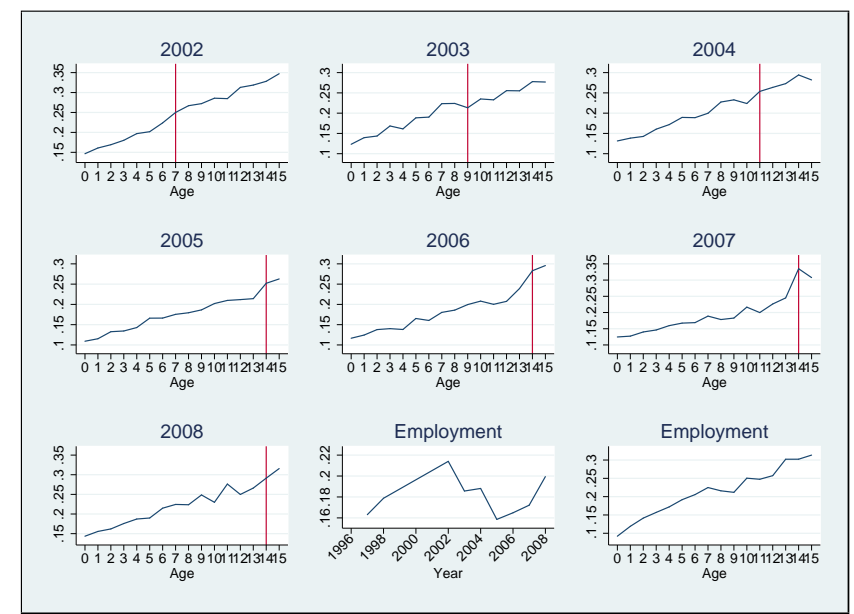

Figure 28: Employment: Predicted (Bottom 50) 
Table 1: Sample Comparison

\begin{tabular}{|c|c|c|c|c|c|c|c|c|c|}
\hline & All & Mothers & $\begin{array}{c}\text { Full } \\
\text { Sample }\end{array}$ & $\begin{array}{l}\text { Mothers } \\
\text { with } \\
\text { Eligible } \\
\text { Child } \\
\end{array}$ & $\begin{array}{l}\text { Black } \\
\text { Mothers } \\
\text { Eligible } \\
\text { Child }\end{array}$ & $\begin{array}{r}\text { Black } \\
\text { Mothers } \\
+-1 \\
\end{array}$ & $\begin{array}{r}\text { Black } \\
\text { Mothers } \\
+-2 \\
\end{array}$ & $\begin{array}{c}\text { Plus Minus } \\
\text { 1 Sample }\end{array}$ & $\begin{array}{l}\text { Plus Minus } \\
2 \text { Sample }\end{array}$ \\
\hline 1997 & 49,469 & 15,583 & 12,222 & 10,315 & 8,422 & 3,261 & 5,567 & 1,380 & 2,697 \\
\hline 1998 & 29,495 & 10,091 & 7,749 & 6,621 & 5,283 & 1,982 & 3,479 & 890 & 1,799 \\
\hline 2002 & 38,211 & 12,888 & 9,725 & 8,139 & 6,358 & 2,188 & 3,968 & 1,165 & 2,381 \\
\hline 2003 & 37,819 & 12,314 & 9,261 & 8,807 & 6,814 & 1,939 & 3,592 & 838 & 1,718 \\
\hline 2004 & 36,760 & 12,091 & 9,159 & 9,572 & 7,410 & 1,817 & 3,258 & 621 & 1,255 \\
\hline 2005 & 39,638 & 13,484 & 10,349 & 12,041 & 9,359 & 1,988 & 3,290 & 421 & 853 \\
\hline 2006 & 39,019 & 12,689 & 9,752 & 11,273 & 8,760 & 1,770 & 3,018 & 424 & 820 \\
\hline 2007 & 40,469 & 13,256 & 10,276 & 11,798 & 9,263 & 1,889 & 3,141 & 459 & 862 \\
\hline 2008 & 34,180 & 11,336 & 9,277 & 10,006 & 8,286 & 1,525 & 2,685 & 387 & 794 \\
\hline
\end{tabular}

$\overline{\text { All individuals in these samples are aged } 20 \text { to 45. Observations from } 1997 \text { and } 1998 \text { come from the October Household }}$ Survey, and from the General Household Survey for years 2002- 2008. The plus minus 1 sample refers to the sample of mothers whose youngest child is aged within a year of the age eligibility cutoff. For example, plus minus 1 in 2002 refers to mothers with children aged 6 and 7 (the cutoff is 7). Similarly the plus minus 2 sample refers to those whose children are aged within 2 years of the cutoff (aged 5, 6, 7 and 8 ). The full sample refers to black mothers who have at least one child. 
Table 2: Labour Market Outcomes - Level Estimates of the Individual CSG Receipt Effect

Age Limit

Labour Force Participant

(Broad)

Unemployed (Broad)

Conditional on Participation

Employed

\begin{tabular}{|c|c|c|c|c|c|c|}
\hline 2003 & 2004 & 2005 & 2006 & 2007 & 2008 & Pooled \\
\hline 9 & 11 & 14 & 14 & 14 & 14 & 14 \\
\hline (1) & (2) & (3) & (4) & $(5)$ & (6) & (7) \\
\hline \multicolumn{7}{|c|}{ Plus Minus 2 Sample } \\
\hline $\begin{array}{l}-0.02 \\
(0.03)\end{array}$ & $\begin{array}{l}-0.01 \\
(0.03)\end{array}$ & $\begin{array}{c}0.01 \\
(0.05)\end{array}$ & $\begin{array}{c}0.01 \\
(0.03)\end{array}$ & $\begin{array}{c}0.02 \\
(0.03)\end{array}$ & $\begin{array}{c}0.02 \\
(0.03)\end{array}$ & $\begin{array}{c}0.00 \\
(0.01)\end{array}$ \\
\hline $\begin{array}{c}0.02 \\
(0.04)\end{array}$ & $\begin{array}{c}0.05 \\
(0.04)\end{array}$ & $\begin{array}{c}0.01 \\
(0.07)\end{array}$ & $\begin{array}{c}0.08 \\
(0.05)\end{array}$ & $\begin{array}{c}0.10 \\
(0.04)\end{array}$ & $\begin{array}{c}0.07 \\
(0.04)\end{array}$ & $\begin{array}{c}0.06 \\
(0.02)\end{array}$ \\
\hline $\begin{array}{l}-0.01 \\
(0.03)\end{array}$ & $\begin{array}{l}-0.05 \\
(0.04)\end{array}$ & $\begin{array}{c}0.00 \\
(0.07)\end{array}$ & $\begin{array}{l}-0.06 \\
(0.04)\end{array}$ & $\begin{array}{c}-0.06 \\
(0.04)\end{array}$ & $\begin{array}{l}-0.04 \\
(0.04)\end{array}$ & $\begin{array}{l}-0.04 \\
(0.02)\end{array}$ \\
\hline 1,709 & 1,244 & 846 & 814 & 855 & 787 & 6,255 \\
\hline \multicolumn{7}{|c|}{ Full Sample } \\
\hline $\begin{array}{c}0.01 \\
(0.01)\end{array}$ & $\begin{array}{c}0.02 \\
(0.01)\end{array}$ & $\begin{array}{c}0.03 \\
(0.01)\end{array}$ & $\begin{array}{c}0.01 \\
(0.01)\end{array}$ & $\begin{array}{c}0.03 \\
(0.01)\end{array}$ & $\begin{array}{c}0.02 \\
(0.01)\end{array}$ & $\begin{array}{c}0.02 \\
(0.00)\end{array}$ \\
\hline 0.06 & 0.09 & 0.09 & 0.09 & 0.10 & 0.15 & 0.12 \\
\hline $\begin{array}{l}(0.01) \\
-0.04\end{array}$ & $\begin{array}{c}(0.01) \\
-0.07\end{array}$ & $\begin{array}{c}(0.01) \\
-0.06\end{array}$ & $\begin{array}{c}(0.01) \\
-0.07\end{array}$ & $\begin{array}{l}(0.01) \\
-0.07\end{array}$ & $\begin{array}{c}(0.01) \\
-0.11\end{array}$ & $\begin{array}{l}(0.01) \\
-0.09\end{array}$ \\
\hline$(0.01)$ & $(0.01)$ & $(0.01)$ & $(0.01)$ & $(0.01)$ & $(0.01)$ & $(0.01)$ \\
\hline 9,204 & 9,109 & 10,288 & 9,716 & 10,220 & 9,190 & 57,727 \\
\hline
\end{tabular}

Labour Force Participant

(Broad)

Unemployed (Broad)

Conditional on Participation

Employed

Number of Observations

The sample includes black mothers aged 20 to 45 whose youngest child is aged within 2 years of the age eligibility cutoff. The table reports the coefficient on having an age eligible child in a specification which controls for household income, or the coefficient on individual report of grant receipt. Standard Errors are reported in parentheses. The specification includes age, years of education, a marital status dummy, household income (based on salaries and pensions), province dummies. Clustering by PSU does not change the results significantly. The pooled sample includes years 2005, 2006, 2007, 2008. 
Table 3: Labour Market Outcomes - Level Estimates of the Age Eligibility Effect

Age Limit

Placebo Treatment

\begin{tabular}{|c|c|c|c|c|c|c|c|c|c|}
\hline \multirow[t]{2}{*}{ Age Limit } & $\frac{0}{(1)}$ & 7 & 9 & 11 & 14 & 14 & 14 & 14 & $\frac{14}{(9)}$ \\
\hline & \multicolumn{9}{|c|}{ Plus Minus 2 Sample } \\
\hline $\begin{array}{l}\text { Labour Force Participant } \\
\text { (Broad) }\end{array}$ & $\begin{array}{c}0.00 \\
(0.02)\end{array}$ & $\begin{array}{l}-0.02 \\
(0.01)\end{array}$ & $\begin{array}{c}0.01 \\
(0.02)\end{array}$ & $\begin{array}{c}0.01 \\
(0.02)\end{array}$ & $\begin{array}{c}0.04 \\
(0.03)\end{array}$ & $\begin{array}{c}0.00 \\
(0.03)\end{array}$ & $\begin{array}{c}0.03 \\
(0.03)\end{array}$ & $\begin{array}{c}0.00 \\
(0.03)\end{array}$ & $\begin{array}{c}0.02 \\
(0.01)\end{array}$ \\
\hline Unemployed (Broad) & -0.04 & 0.03 & -0.02 & -0.01 & 0.01 & 0.01 & 0.03 & 0.09 & 0.03 \\
\hline Conditional on Participation & $(0.03)$ & $(0.02)$ & $(0.02)$ & $(0.03)$ & $(0.04)$ & $(0.04)$ & $(0.04)$ & $(0.04)$ & $(0.02)$ \\
\hline Employed & $\begin{array}{c}0.03 \\
(0.02)\end{array}$ & $\begin{array}{l}-0.03 \\
(0.02)\end{array}$ & $\begin{array}{c}0.03 \\
(0.02)\end{array}$ & $\begin{array}{c}0.02 \\
(0.03)\end{array}$ & $\begin{array}{c}0.02 \\
(0.03)\end{array}$ & $\begin{array}{l}-0.01 \\
(0.03)\end{array}$ & $\begin{array}{l}-0.01 \\
(0.03)\end{array}$ & $\begin{array}{l}-0.07 \\
(0.03)\end{array}$ & $\begin{array}{l}-0.01 \\
(0.02)\end{array}$ \\
\hline \multirow[t]{2}{*}{ Number of Observations } & 1,873 & 2,368 & 1,710 & 1,246 & 846 & 815 & 858 & 789 & 3,308 \\
\hline & \multicolumn{9}{|c|}{ Full Sample } \\
\hline $\begin{array}{l}\text { Labour Force Participant } \\
\text { (Broad) }\end{array}$ & $\begin{array}{l}-0.01 \\
(0.01)\end{array}$ & $\begin{array}{l}-0.02 \\
(0.01)\end{array}$ & $\begin{array}{c}0.01 \\
(0.01)\end{array}$ & $\begin{array}{c}0.03 \\
(0.01)\end{array}$ & $\begin{array}{l}0.05 \\
(0.01)\end{array}$ & $\begin{array}{c}0.02 \\
(0.01)\end{array}$ & $\begin{array}{c}0.05 \\
(0.01)\end{array}$ & $\begin{array}{c}0.04 \\
(0.02)\end{array}$ & $\begin{array}{c}0.04 \\
(0.01)\end{array}$ \\
\hline Unemployed (Broad) & 0.04 & 0.05 & 0.05 & 0.05 & 0.06 & 0.09 & 0.08 & 0.06 & 0.07 \\
\hline Conditional on Participation & $(0.01)$ & $(0.01)$ & $(0.01)$ & $(0.02)$ & $(0.02)$ & $(0.02)$ & $(0.02)$ & $(0.02)$ & $(0.01)$ \\
\hline Employed & $\begin{array}{l}-0.04 \\
(0.01)\end{array}$ & $\begin{array}{l}-0.05 \\
(0.01)\end{array}$ & $\begin{array}{l}-0.04 \\
(0.01)\end{array}$ & $\begin{array}{l}-0.03 \\
(0.01)\end{array}$ & $\begin{array}{l}-0.03 \\
(0.02)\end{array}$ & $\begin{array}{l}-0.07 \\
(0.02)\end{array}$ & $\begin{array}{l}-0.05 \\
(0.02)\end{array}$ & $\begin{array}{l}-0.03 \\
(0.02)\end{array}$ & $\begin{array}{l}-0.04 \\
(0.01)\end{array}$ \\
\hline Number of Observations & 12,198 & 9,683 & 9,211 & 9,114 & 10,301 & 9,730 & 10,249 & 9,233 & 39,513 \\
\hline
\end{tabular}

The sample includes black mothers aged 20 to 45. The table reports the coefficient on having an age eligible child in a specification which controls for household income, or the coefficient on individual report of grant receipt. Standard Errors are reported in parentheses. The specification includes age, years of education, a marital status dummy, household income (based on salaries and pensions), province dummies. Clustering by PSU does not change the results significantly. The pooled sample includes years 2005, 2006, 2007, 20ก8 
Table 4: Labour Market Outcomes - Difference in Difference Estimator

\begin{tabular}{|c|c|c|c|c|c|c|c|c|c|}
\hline$\overline{\overline{\text { Pre }}}$ & '97/'98 & '97/'98 & '97/'98 & '97/'98 & '97/'98 & '97/'98 & '97/'98 & $\overline{\prime \prime 97 / ' 98}$ & $\overline{1997}$ \\
\hline Post & 2002 & 2003 & 2004 & 2005 & 2006 & 2007 & 2008 & $2005-2008$ & 1998 \\
\hline \multirow[t]{3}{*}{ Age Limit } & 7 & 9 & 11 & 14 & 14 & 14 & 14 & 14 & 7 \\
\hline & $(1)$ & (2) & (3) & $(4)$ & (5) & (6) & (7) & (8) & (9) \\
\hline & \multicolumn{9}{|c|}{ Age Eligibility } \\
\hline $\begin{array}{l}\text { Labour Force Participant } \\
\text { (Broad) }\end{array}$ & $\begin{array}{l}0.00 \\
(0.02)\end{array}$ & $\begin{array}{c}0.03 \\
(0.03)\end{array}$ & $\begin{array}{c}0.05 \\
(0.03)\end{array}$ & $\begin{array}{c}0.10 \\
(0.04)\end{array}$ & $\begin{array}{c}0.07 \\
(0.04)\end{array}$ & $\begin{array}{c}0.09 \\
(0.04)\end{array}$ & $\begin{array}{c}0.06 \\
(0.04)\end{array}$ & $\begin{array}{c}0.05 \\
(0.03)\end{array}$ & $\begin{array}{l}-0.02 \\
(0.03)\end{array}$ \\
\hline Unemployed (Broad) & 0.03 & 0.02 & -0.08 & 0.06 & 0.06 & 0.07 & 0.12 & 0.07 & 0.05 \\
\hline Conditional on Participation & $(0.03)$ & $(0.04)$ & $(0.04)$ & $(0.05)$ & $(0.05)$ & $(0.05)$ & $(0.05)$ & $(0.03)$ & $(0.04)$ \\
\hline Employed & -0.03 & 0.01 & 0.08 & 0.01 & -0.02 & 0.00 & -0.07 & -0.03 & -0.04 \\
\hline & $(0.03)$ & $(0.03)$ & $(0.04)$ & $(0.05)$ & $(0.05)$ & $(0.05)$ & $(0.05)$ & $(0.03)$ & $(0.03)$ \\
\hline \multirow[t]{2}{*}{ Number of Observations } & 5,058 & 3,583 & 2,598 & 1,681 & 1,650 & 1,693 & 1,624 & 4,710 & 4,484 \\
\hline & \multicolumn{9}{|c|}{ Bottom 50th percentile of Household Income } \\
\hline Labour Force Participant & 0.01 & -0.03 & 0.12 & 0.09 & 0.10 & 0.09 & 0.05 & 0.05 & 0.01 \\
\hline (Broad) & $(0.03)$ & $(0.04)$ & $(0.05)$ & $(0.06)$ & $(0.06)$ & $(0.06)$ & $(0.07)$ & $(0.04)$ & $(0.04)$ \\
\hline Unemployed (Broad) & -0.03 & 0.06 & -0.07 & 0.21 & 0.15 & 0.18 & 0.22 & 0.16 & -0.01 \\
\hline Conditional on Participation & $(0.04)$ & $(0.05)$ & $(0.06)$ & $(0.08)$ & $(0.08)$ & $(0.07)$ & $(0.08)$ & $(0.05)$ & $(0.05)$ \\
\hline Employed & 0.02 & -0.04 & 0.10 & -0.09 & -0.04 & -0.10 & -0.13 & -0.09 & 0.01 \\
\hline & & & & & & & & & \\
\hline Number of Observations & 2,656 & 1,883 & 1,325 & 826 & 784 & 851 & 775 & 2,310 & 2,409 \\
\hline
\end{tabular}


Table 5: Modified Difference in Difference Estimates

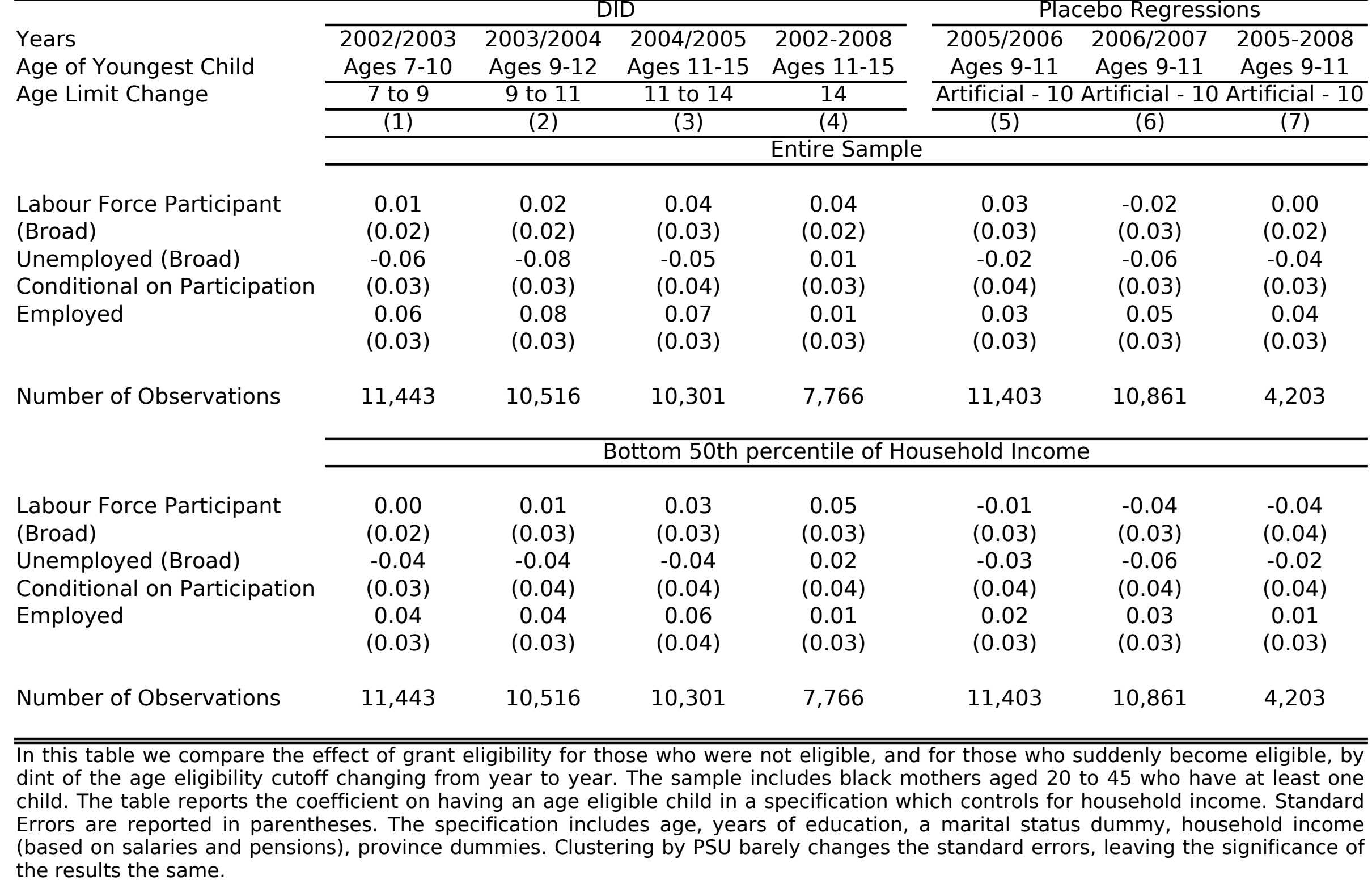


Table 6: Modified Difference in Difference Estimates, Heterogenous Treatment Effects

\begin{tabular}{|c|c|c|c|c|c|c|c|}
\hline \multirow[t]{2}{*}{ Group: } & $\begin{array}{c}\text { Full Sample } \\
(1)\end{array}$ & $\begin{array}{c}\text { Bottom } 50^{\text {th }} \\
(2)\end{array}$ & $\begin{array}{c}\text { Top } 50^{\text {th }} \\
(3)\end{array}$ & $\begin{array}{c}\text { Matric } \\
(4)\end{array}$ & $\begin{array}{c}\text { No Matric } \\
(5)\end{array}$ & $\begin{array}{c}\text { Married } \\
(6)\end{array}$ & $\begin{array}{c}\text { Not Married } \\
(7) \\
\end{array}$ \\
\hline & \multicolumn{7}{|c|}{ Panel A: } \\
\hline $\begin{array}{l}\text { Labour Force Participant } \\
\text { (Broad) }\end{array}$ & $\begin{array}{c}0.02 \\
(0.02)\end{array}$ & $\begin{array}{c}0.01 \\
(0.03)\end{array}$ & $\begin{array}{c}0.03 \\
(0.02)\end{array}$ & $\begin{array}{c}0.03 \\
(0.03)\end{array}$ & $\begin{array}{c}0.02 \\
(0.03)\end{array}$ & $\begin{array}{c}0.04 \\
(0.03)\end{array}$ & $\begin{array}{c}0.00 \\
(0.03)\end{array}$ \\
\hline $\begin{array}{l}\text { Unemployed (Broad) } \\
\text { Conditional on Participation }\end{array}$ & $\begin{array}{l}-0.08 \\
(0.03)\end{array}$ & $\begin{array}{l}-0.04 \\
(0.04)\end{array}$ & $\begin{array}{l}-0.11 \\
(0.03)\end{array}$ & $\begin{array}{l}-0.07 \\
(0.04)\end{array}$ & $\begin{array}{l}-0.10 \\
(0.03)\end{array}$ & $\begin{array}{l}-0.09 \\
(0.04)\end{array}$ & $\begin{array}{l}-0.08 \\
(0.04)\end{array}$ \\
\hline Employed & $\begin{array}{c}0.08 \\
(0.03)\end{array}$ & $\begin{array}{c}0.04 \\
(0.03)\end{array}$ & $\begin{array}{c}0.11 \\
(0.03)\end{array}$ & $\begin{array}{c}0.09 \\
(0.04)\end{array}$ & $\begin{array}{c}0.09 \\
(0.03)\end{array}$ & $\begin{array}{c}0.09 \\
(0.03)\end{array}$ & $\begin{array}{c}0.08 \\
(0.03)\end{array}$ \\
\hline \multirow[t]{2}{*}{ Number of Observations } & 10,516 & 10,516 & 10,516 & 10,516 & 10,516 & 10,516 & 10,516 \\
\hline & \multicolumn{7}{|c|}{ Panel B: } \\
\hline Group: & Pensioner & No Pensioner & $20 s$ & $30 s$ & $40 s$ & & White \\
\hline $\begin{array}{l}\text { Labour Force Participant } \\
\text { (Broad) }\end{array}$ & $\begin{array}{c}0.01 \\
(0.03)\end{array}$ & $\begin{array}{c}0.02 \\
(0.02)\end{array}$ & $\begin{array}{c}0.09 \\
(0.04)\end{array}$ & $\begin{array}{c}0.04 \\
(0.03)\end{array}$ & $\begin{array}{l}-0.01 \\
(0.03)\end{array}$ & & $\begin{array}{c}0.08 \\
(0.07)\end{array}$ \\
\hline Unemployed (Broad) & -0.10 & -0.08 & -0.14 & -0.09 & -0.06 & & -0.02 \\
\hline Conditional on Participation & $(0.04)$ & $(0.03)$ & $(0.06)$ & $(0.04)$ & $(0.04)$ & & $(0.06)$ \\
\hline Employed & $\begin{array}{c}0.09 \\
(0.04)\end{array}$ & $\begin{array}{c}0.08 \\
(0.03)\end{array}$ & $\begin{array}{c}0.15 \\
(0.06)\end{array}$ & $\begin{array}{c}0.10 \\
(0.03)\end{array}$ & $\begin{array}{l}0.05 \\
(0.03)\end{array}$ & & $\begin{array}{c}0.09 \\
(0.07)\end{array}$ \\
\hline Number of Observations & 10,516 & 10,516 & 10,516 & 10,516 & 10,516 & & 1,219 \\
\hline
\end{tabular}

This table replicates table 5, column 2, for different groups. The sample includes black mothers aged 20 to 45 who have at least one child. The table reports the coefficient on having an age eligible child in a specification which controls for household income. Standard Errors are reported in parentheses. The specification includes age, years of education, a marital status dummy, household income (based on salaries and pensions), province dummies. Clustering by PSU barely changes the standard errors, leaving the significance of the results the same. 
Table 7: Instrumental Variables Estimates: CSG receipt instrumented for by Eligibility.

Age Limit

Labour Force Participant - Broad

Unemployment - Broad

Conditional on Participation

Employed

Number of Observations

abour Force Participant - Broad

Unemployment - Broad

Conditional on Participation

Employed

Number of Observations

\begin{tabular}{cccc}
\multicolumn{4}{c}{ Full Sample } \\
\hline 2006 & 2007 & 2008 & Pooled \\
\hline 14 & 14 & 14 & 14 \\
\hline$(1)$ & $(2)$ & $(3)$ & $(4)$
\end{tabular}

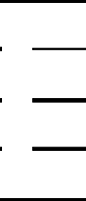

Plus Minus 1

\section{Bottom 50 Percentiles of Income}

\begin{tabular}{|c|c|c|c|c|c|c|c|}
\hline 0.03 & 0.03 & 0.16 & 0.06 & -0.06 & 0.20 & 0.13 & 0.08 \\
\hline$(0.17)$ & $(0.10)$ & $(0.13)$ & $(0.07)$ & $(0.24)$ & $(0.12)$ & $(0.15)$ & $(0.09)$ \\
\hline-0.27 & 0.09 & 0.28 & 0.07 & 0.30 & -0.01 & 0.27 & 0.15 \\
\hline$(0.24)$ & $(0.12)$ & $(0.20)$ & $(0.10)$ & $(0.28)$ & $(0.12)$ & $(0.22)$ & $(0.11)$ \\
\hline 0.20 & -0.07 & -0.11 & -0.02 & -0.08 & 0.08 & -0.11 & -0.04 \\
\hline$(0.21)$ & $(0.13)$ & $(0.16)$ & $(0.09)$ & $(0.22)$ & $(0.12)$ & $(0.15)$ & $(0.09)$ \\
\hline 421 & 455 & 383 & 1,259 & 199 & 246 & 192 & 637 \\
\hline
\end{tabular}

Plus Minus 2

$\begin{array}{cccccccc}0.01 & 0.09 & 0.00 & 0.04 & 0.09 & 0.11 & 0.02 & 0.06 \\ (0.09) & (0.07) & (0.07) & (0.04) & (0.11) & (0.09) & (0.10) & (0.06) \\ 0.04 & 0.07 & 0.26 & 0.11 & 0.09 & 0.09 & 0.32 & 0.15 \\ (0.12) & (0.08) & (0.10) & (0.06) & (0.12) & (0.09) & (0.12) & (0.06) \\ -0.03 & 0.00 & -0.19 & -0.06 & 0.04 & -0.04 & -0.19 & -0.06 \\ (0.11) & (0.08) & (0.08) & (0.05) & (0.11) & (0.08) & (0.09) & (0.05) \\ & & & & & & & \\ 814 & 855 & 787 & 2,456 & 384 & 451 & 374 & 1,209\end{array}$

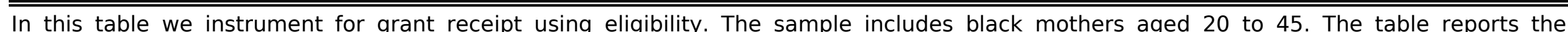




dummies. Clustering by PSU does not change the results significantly. The pooled sample includes years $2006,2007,2008$. 


\begin{tabular}{|c|c|c|c|c|c|c|}
\hline Sample & & $\begin{array}{c}\text { \# Obs } \\
(1)\end{array}$ & $\frac{\text { \# Children }}{(2)}$ & $\begin{array}{c}\text { Has an } \\
\text { Eligible Child } \\
(3)\end{array}$ & $\begin{array}{c}\begin{array}{c}\text { Household } \\
\text { Income }\end{array} \\
(4)\end{array}$ & $\begin{array}{c}\begin{array}{c}\text { Household } \\
\text { Size }\end{array} \\
\text { (5) }\end{array}$ \\
\hline Mothers & $\begin{array}{l}\text { Birth History } \\
\text { Mother Pcode }\end{array}$ & $\begin{array}{l}12,702 \\
12,888\end{array}$ & $\begin{array}{l}2.19 \\
2.20\end{array}$ & $\begin{array}{l}0.63 \\
0.63\end{array}$ & $\begin{array}{l}2551.2 \\
2549.3\end{array}$ & $\begin{array}{l}5.95 \\
5.96\end{array}$ \\
\hline Full Sample (Black Mothers) & $\begin{array}{l}\text { Birth History } \\
\text { Mother Pcode }\end{array}$ & $\begin{array}{l}9,569 \\
9,725\end{array}$ & $\begin{array}{l}2.24 \\
2.25\end{array}$ & $\begin{array}{l}0.66 \\
0.65\end{array}$ & $\begin{array}{l}1683.8 \\
1685.6\end{array}$ & $\begin{array}{l}6.26 \\
6.27\end{array}$ \\
\hline Mothers with Eligible Child & $\begin{array}{l}\text { Birth History } \\
\text { Mother Pcode }\end{array}$ & $\begin{array}{l}8,047 \\
8,139\end{array}$ & $\begin{array}{l}2.26 \\
2.27\end{array}$ & $\begin{array}{l}0.99 \\
1.00\end{array}$ & $\begin{array}{l}2297.1 \\
2294.1\end{array}$ & $\begin{array}{l}6.23 \\
6.25\end{array}$ \\
\hline Black Mothers with Eligible Child & $\begin{array}{l}\text { Birth History } \\
\text { Mother Pcode }\end{array}$ & $\begin{array}{l}6,282 \\
6,358\end{array}$ & $\begin{array}{l}2.32 \\
2.33\end{array}$ & $\begin{array}{l}0.99 \\
1.00\end{array}$ & $\begin{array}{l}1580.5 \\
1579.9\end{array}$ & $\begin{array}{l}6.52 \\
6.53\end{array}$ \\
\hline $\begin{array}{l}\text { Black Mothers with Eligible Child within } \\
1 \text { year of cutoff }\end{array}$ & $\begin{array}{l}\text { Birth History } \\
\text { Mother Pcode }\end{array}$ & $\begin{array}{l}2,162 \\
2,188\end{array}$ & $\begin{array}{l}2.94 \\
2.95\end{array}$ & $\begin{array}{l}0.76 \\
0.76\end{array}$ & $\begin{array}{l}1659.0 \\
1662.1\end{array}$ & $\begin{array}{l}6.71 \\
6.72\end{array}$ \\
\hline $\begin{array}{l}\text { Black Mothers with Eligible Child within } \\
2 \text { years of cutoff }\end{array}$ & $\begin{array}{l}\text { Birth History } \\
\text { Mother Pcode }\end{array}$ & $\begin{array}{l}3,922 \\
3,968\end{array}$ & $\begin{array}{l}2.82 \\
2.83\end{array}$ & $\begin{array}{l}0.74 \\
0.74\end{array}$ & $\begin{array}{l}1666.4 \\
1676.6\end{array}$ & $\begin{array}{l}6.64 \\
6.65\end{array}$ \\
\hline Plus Minus 1 Sample & $\begin{array}{l}\text { Birth History } \\
\text { Mother Pcode }\end{array}$ & $\begin{array}{l}1,148 \\
1,165\end{array}$ & $\begin{array}{l}2.37 \\
2.38\end{array}$ & $\begin{array}{l}0.55 \\
0.55\end{array}$ & $\begin{array}{l}1886.7 \\
1893.2\end{array}$ & $\begin{array}{l}6.18 \\
6.19\end{array}$ \\
\hline Plus Minus 2 Sample & $\begin{array}{l}\text { Birth History } \\
\text { Mother Pcode }\end{array}$ & $\begin{array}{l}2,347 \\
2,381\end{array}$ & $\begin{array}{l}2.37 \\
2.37\end{array}$ & $\begin{array}{l}0.57 \\
0.57\end{array}$ & $\begin{array}{l}1811.7 \\
1829.4\end{array}$ & $\begin{array}{l}6.24 \\
6.25\end{array}$ \\
\hline
\end{tabular}

All individuals are aged 20 to 45 . Figures are unweighted, although weighted figures are very similar. Hypothesis tests show some significant differences, but most differences are very small. Plus Minus 2 Household income is significantly different, as a result of imputed pension income which is calculated in 2002 based on the numbers of pensioners present in the household, as individual grant receipt was not recorded in this year. 
Appendix Table 2: Child Support Grant Receipt

\begin{tabular}{|c|c|c|c|c|c|c|c|c|c|}
\hline & All & Mothers & $\begin{array}{l}\text { Black } \\
\text { Mothers }\end{array}$ & $\begin{array}{l}\text { Mothers } \\
\text { with } \\
\text { Eligible } \\
\text { Child }\end{array}$ & $\begin{array}{l}\text { Black } \\
\text { Mothers } \\
\text { Eligible } \\
\text { Child }\end{array}$ & $\begin{array}{r}\text { Black } \\
\text { Mothers } \\
+-1\end{array}$ & $\begin{array}{r}\text { Black } \\
\text { Mothers } \\
+-2\end{array}$ & $\begin{array}{l}\text { Plus Minus PI } \\
1 \text { Sample } 2\end{array}$ & $\begin{array}{r}\text { us Minus } \\
\text { Sample }\end{array}$ \\
\hline & $(1)$ & $(2)$ & (3) & $(4)$ & $(5)$ & $(6)$ & $(7)$ & $(8)$ & (9) \\
\hline Year & \multicolumn{9}{|c|}{ Household CSG Receipt } \\
\hline 1997 & 0.00 & 0.00 & 0.00 & 0.00 & 0.00 & 0.00 & 0.00 & 0.00 & 0.00 \\
\hline 1998 & 0.00 & 0.00 & 0.00 & 0.00 & 0.00 & 0.00 & 0.00 & 0.00 & 0.00 \\
\hline 2002 & 0.11 & 0.18 & 0.21 & 0.23 & 0.27 & 0.24 & 0.22 & 0.19 & 0.18 \\
\hline 2003 & 0.20 & 0.31 & 0.38 & 0.39 & 0.46 & 0.34 & 0.35 & 0.15 & 0.19 \\
\hline 2004 & 0.28 & 0.44 & 0.52 & 0.51 & 0.59 & 0.47 & 0.48 & 0.25 & 0.29 \\
\hline 2005 & 0.36 & 0.53 & 0.61 & 0.57 & 0.65 & 0.56 & 0.55 & 0.27 & 0.27 \\
\hline 2006 & 0.36 & 0.54 & 0.62 & 0.58 & 0.67 & 0.57 & 0.58 & 0.30 & 0.36 \\
\hline 2007 & 0.40 & 0.59 & 0.68 & 0.64 & 0.72 & 0.64 & 0.65 & 0.45 & 0.47 \\
\hline \multirow[t]{2}{*}{2008} & 0.42 & 0.61 & 0.69 & 0.66 & 0.74 & 0.67 & 0.66 & 0.45 & 0.48 \\
\hline & \multicolumn{9}{|c|}{ Individual CSG Receipt } \\
\hline 1997 & 0.00 & 0.00 & 0.00 & 0.00 & 0.00 & 0.00 & 0.00 & 0.00 & 0.00 \\
\hline 1998 & 0.00 & 0.00 & 0.00 & 0.00 & 0.00 & 0.00 & 0.00 & 0.00 & 0.00 \\
\hline 2002 & 0.00 & 0.00 & 0.00 & 0.00 & 0.00 & 0.00 & 0.00 & 0.00 & 0.00 \\
\hline 2003 & 0.26 & 0.26 & 0.31 & 0.36 & 0.42 & 0.28 & 0.30 & 0.06 & 0.11 \\
\hline 2004 & 0.37 & 0.37 & 0.44 & 0.47 & 0.54 & 0.39 & 0.41 & 0.09 & 0.15 \\
\hline 2005 & 0.46 & 0.46 & 0.54 & 0.52 & 0.59 & 0.49 & 0.48 & 0.05 & 0.07 \\
\hline 2006 & 0.48 & 0.48 & 0.56 & 0.54 & 0.62 & 0.52 & 0.53 & 0.16 & 0.22 \\
\hline 2007 & 0.53 & 0.53 & 0.61 & 0.60 & 0.67 & 0.59 & 0.59 & 0.31 & 0.33 \\
\hline 2008 & 0.55 & 0.55 & 0.63 & 0.62 & 0.70 & 0.62 & 0.61 & 0.31 & 0.35 \\
\hline
\end{tabular}

All individuals in these samples are aged 20 to 45. Observations from 1997 and 1998 come from the October Household Survey, and from the General Household Survey for years 2002- 2008. For 2002, 23\% of Mothers with Eligible Children lived in households which reported receiving the child support grant. These means are unweighted, however weighted means do not differ greatly at all. 
Appendix Table 3: Balancing Tests

\begin{tabular}{|c|c|c|c|c|c|c|}
\hline & \multicolumn{2}{|c|}{ Full Sample } & \multicolumn{2}{|c|}{ Plus Minus 1} & \multicolumn{2}{|c|}{ Plus Minus 2} \\
\hline & $\frac{\text { Control }}{(1)}$ & $\frac{\text { T-C Diff }}{(2)}$ & $\begin{array}{c}\text { Control } \\
(3) \\
\end{array}$ & $\frac{\text { T-C Diff }}{(4)}$ & $\begin{array}{c}\text { Control } \\
(5)\end{array}$ & $\frac{\text { T-C Diff }}{(6)}$ \\
\hline Age & $\begin{array}{l}38.02 \\
(0.10)\end{array}$ & $\begin{array}{l}-6.71 \\
-55.46\end{array}$ & $\begin{array}{l}35.87 \\
(0.33)\end{array}$ & $\begin{array}{l}-0.71 \\
-1.72\end{array}$ & $\begin{array}{l}36.06 \\
(0.21)\end{array}$ & $\begin{array}{l}-1.43 \\
-5.27\end{array}$ \\
\hline Years Education & $\begin{array}{l}7.79 \\
(0.10)\end{array}$ & $\begin{array}{l}0.88 \\
9.32\end{array}$ & $\begin{array}{c}8.42 \\
(0.23)\end{array}$ & $\begin{array}{l}-0.23 \\
-0.77\end{array}$ & $\begin{array}{l}8.18 \\
(0.16)\end{array}$ & $\begin{array}{l}0.26 \\
1.33\end{array}$ \\
\hline Married & $\begin{array}{c}0.49 \\
(0.01)\end{array}$ & $\begin{array}{l}0.01 \\
0.48\end{array}$ & $\begin{array}{c}0.49 \\
(0.03)\end{array}$ & $\begin{array}{l}0.04 \\
1.29\end{array}$ & $\begin{array}{c}0.49 \\
(0.02)\end{array}$ & $\begin{array}{l}0.00 \\
0.01\end{array}$ \\
\hline Household Size & $\begin{array}{l}5.77 \\
(0.07)\end{array}$ & $\begin{array}{c}0.84 \\
11.41\end{array}$ & $\begin{array}{l}6.34 \\
(0.16)\end{array}$ & $\begin{array}{l}-0.31 \\
-1.63\end{array}$ & $\begin{array}{l}6.18 \\
(0.12)\end{array}$ & $\begin{array}{l}0.08 \\
0.57\end{array}$ \\
\hline Number of Kids & $\begin{array}{c}2.16 \\
(0.03)\end{array}$ & $\begin{array}{c}0.51 \\
15.97\end{array}$ & $\begin{array}{c}2.61 \\
(0.08)\end{array}$ & $\begin{array}{l}0.08 \\
0.70\end{array}$ & $\begin{array}{c}2.52 \\
(0.05)\end{array}$ & $\begin{array}{l}0.14 \\
2.06\end{array}$ \\
\hline Household Income & $\begin{array}{l}1,440.1 \\
(46.36)\end{array}$ & $\begin{array}{l}-202.8 \\
-4.52\end{array}$ & $\begin{array}{l}1,488.4 \\
(117.50)\end{array}$ & $\begin{array}{l}-255.3 \\
-1.83\end{array}$ & $\begin{array}{l}1,411.8 \\
(76.76)\end{array}$ & $\begin{array}{l}-86.3 \\
-0.86\end{array}$ \\
\hline $\begin{array}{l}\text { Labour Force Participant } \\
\text { Broad }\end{array}$ & $\begin{array}{c}0.73 \\
(0.01)\end{array}$ & $\begin{array}{l}-0.10 \\
-10.37\end{array}$ & $\begin{array}{c}0.73 \\
(0.02)\end{array}$ & $\begin{array}{l}-0.02 \\
-0.69\end{array}$ & $\begin{array}{c}0.70 \\
(0.02)\end{array}$ & $\begin{array}{l}-0.01 \\
-0.47\end{array}$ \\
\hline $\begin{array}{l}\text { Unemployment - Broad } \\
\text { Conditional on Participation }\end{array}$ & $\begin{array}{c}0.43 \\
(0.01)\end{array}$ & $\begin{array}{c}0.17 \\
12.86\end{array}$ & $\begin{array}{c}0.50 \\
(0.03)\end{array}$ & $\begin{array}{l}0.01 \\
0.28\end{array}$ & $\begin{array}{c}0.51 \\
(0.02)\end{array}$ & $\begin{array}{l}-0.01 \\
-0.50\end{array}$ \\
\hline Employed & $\begin{array}{c}0.41 \\
(0.01)\end{array}$ & $\begin{array}{l}-0.16 \\
-15.37\end{array}$ & $\begin{array}{c}0.37 \\
(0.03)\end{array}$ & $\begin{array}{l}-0.02 \\
-0.56\end{array}$ & $\begin{array}{c}0.34 \\
(0.02)\end{array}$ & $\begin{array}{l}0.00 \\
0.22\end{array}$ \\
\hline \# Treatment Group & & 10 & 46 & & 1,0 & 88 \\
\hline \# Control Group & 2,7 & 12 & 40 & & $7 \varepsilon$ & \\
\hline Number of Observations & 12, & 222 & 86 & & 1,8 & \\
\hline
\end{tabular}


Appendix Table 4: Individual Child Support Grant Receipt, by Age

\begin{tabular}{lcccccc}
\hline Year & 2003 & 2004 & 2005 & 2006 & 2007 & 2008 \\
Age Limit & 9 & 11 & 14 & 14 & 14 & 14 \\
\cline { 2 - 7 } & $(1)$ & $(2)$ & $(3)$ & $(4)$ & $(5)$ & $(6)$ \\
\cline { 2 - 7 } Age Groups & & & & & & \\
0 & 0.15 & 0.24 & 0.26 & 0.32 & 0.37 & 0.44 \\
1 & 0.38 & 0.49 & 0.54 & 0.57 & 0.64 & 0.66 \\
2 & 0.42 & 0.55 & 0.61 & 0.63 & 0.65 & 0.71 \\
3 & 0.43 & 0.57 & 0.64 & 0.63 & 0.68 & 0.70 \\
4 & 0.41 & 0.57 & 0.63 & 0.64 & 0.68 & 0.69 \\
5 & 0.45 & 0.57 & 0.63 & 0.62 & 0.67 & 0.69 \\
6 & 0.34 & 0.54 & 0.63 & 0.61 & 0.67 & 0.68 \\
7 & 0.23 & 0.50 & 0.57 & 0.59 & 0.66 & 0.68 \\
8 & 0.07 & 0.42 & 0.55 & 0.59 & 0.62 & 0.66 \\
9 & 0.02 & 0.28 & 0.52 & 0.57 & 0.61 & 0.65 \\
10 & 0.01 & 0.10 & 0.42 & 0.51 & 0.59 & 0.63 \\
11 & 0.01 & 0.04 & 0.27 & 0.46 & 0.56 & 0.58 \\
12 & 0.01 & 0.01 & 0.12 & 0.37 & 0.50 & 0.54 \\
13 & 0.00 & 0.01 & 0.05 & 0.28 & 0.38 & 0.47 \\
14 & 0.00 & 0.01 & 0.02 & 0.08 & 0.11 & 0.16 \\
15 & 0.00 & 0.00 & 0.01 & 0.02 & 0.02 & 0.03
\end{tabular}

$\overline{\text { This table shows the age distribution of recipients of the child support grant by year. We }}$ can see the sharp fall in receipt at each age limit. 
Appendix Table 5: Child Support Grant Takeup by Province

\begin{tabular}{|c|c|c|c|c|c|c|c|c|c|c|}
\hline$\overline{\overline{\text { Year }}}$ & 1997 & 1998 & 2002 & 2003 & 2004 & 2005 & 2006 & 2007 & 2008 & All Years \\
\hline \multirow{3}{*}{ Age Limit } & 7 & 7 & 7 & 9 & 11 & 14 & 14 & 14 & 14 & \\
\hline & (1) & $(2)$ & (3) & (4) & (5) & (6) & $(7)$ & $(8)$ & (9) & (10) \\
\hline & \multicolumn{9}{|c|}{ Panel A: Age Eligibility } & \\
\hline Western Cape & 0.65 & 0.69 & 0.67 & 0.73 & 0.79 & 0.90 & 0.87 & 0.89 & 0.86 & 0.78 \\
\hline Eastern Cape & 0.73 & 0.70 & 0.66 & 0.76 & 0.84 & 0.89 & 0.91 & 0.91 & 0.91 & 0.81 \\
\hline Northern Cape & 0.67 & 0.61 & 0.59 & 0.74 & 0.79 & 0.84 & 0.88 & 0.89 & 0.90 & 0.79 \\
\hline Free State & 0.63 & 0.64 & 0.61 & 0.70 & 0.76 & 0.89 & 0.89 & 0.90 & 0.88 & 0.77 \\
\hline KwaZulu-Natal & 0.71 & 0.69 & 0.65 & 0.72 & 0.81 & 0.91 & 0.89 & 0.89 & 0.90 & 0.81 \\
\hline North West & 0.67 & 0.67 & 0.69 & 0.75 & 0.82 & 0.90 & 0.89 & 0.91 & 0.89 & 0.79 \\
\hline Gauteng & 0.63 & 0.62 & 0.60 & 0.69 & 0.76 & 0.88 & 0.89 & 0.88 & 0.87 & 0.75 \\
\hline Mpumalanga & 0.69 & 0.69 & 0.66 & 0.75 & 0.82 & 0.91 & 0.90 & 0.91 & 0.89 & 0.80 \\
\hline Limpopo & 0.74 & 0.74 & 0.69 & 0.78 & 0.85 & 0.93 & 0.93 & 0.92 & 0.90 & 0.83 \\
\hline \multirow[t]{2}{*}{ Number of Observations } & 12,222 & 7,749 & 9,725 & 9,261 & 9,159 & 10,349 & 9,752 & 10,276 & 9,277 & 10,232 \\
\hline & \multicolumn{10}{|c|}{ Panel B: Household CSG Receipt } \\
\hline Western Cape & 0.00 & 0.00 & 0.26 & 0.44 & 0.52 & 0.46 & 0.47 & 0.55 & 0.55 & 0.47 \\
\hline Eastern Cape & 0.00 & 0.00 & 0.20 & 0.39 & 0.48 & 0.65 & 0.69 & 0.74 & 0.77 & 0.56 \\
\hline Northern Cape & 0.00 & 0.00 & 0.21 & 0.30 & 0.48 & 0.48 & 0.45 & 0.54 & 0.72 & 0.49 \\
\hline Free State & 0.00 & 0.00 & 0.21 & 0.39 & 0.53 & 0.63 & 0.59 & 0.67 & 0.70 & 0.53 \\
\hline KwaZulu-Natal & 0.00 & 0.00 & 0.18 & 0.33 & 0.48 & 0.64 & 0.64 & 0.72 & 0.73 & 0.56 \\
\hline North West & 0.00 & 0.00 & 0.25 & 0.36 & 0.57 & 0.62 & 0.63 & 0.73 & 0.70 & 0.54 \\
\hline Gauteng & 0.00 & 0.00 & 0.15 & 0.26 & 0.36 & 0.42 & 0.45 & 0.47 & 0.53 & 0.37 \\
\hline Mpumalanga & 0.00 & 0.00 & 0.25 & 0.43 & 0.59 & 0.65 & 0.67 & 0.72 & 0.73 & 0.58 \\
\hline Limpopo & 0.00 & 0.00 & 0.24 & 0.47 & 0.64 & 0.70 & 0.69 & 0.69 & 0.73 & 0.58 \\
\hline Number of Observations & 12,222 & 7,749 & 9,725 & 9,261 & 9,159 & 10,349 & 9,752 & 10,276 & 9,277 & 10,232 \\
\hline
\end{tabular}

The sample includes black mothers aged 20 to 45 with at least one child - the full sample referred to in table 1. 
Appendix Table 6: Mechanisms - The effect of Individual Child Support Grant Receipt on 3 Outcomes

Age Limit

Number of Kids

Attending School

Number of Kids not Attending

Due to Lack of School Fees

\begin{tabular}{ccc}
\hline 2003 & 2004 & 200 \\
\hline 9 & 11 & 14 \\
\hline$(1)$ & $(2)$ & $(3)$
\end{tabular}

14

2006

Plus Minus 2 Sample

Number of Observations

\begin{tabular}{|c|c|c|c|c|c|c|}
\hline \multicolumn{7}{|c|}{ Plus Minus 2 Sample } \\
\hline 0.10 & 0.12 & 0.09 & 0.09 & 0.08 & 0.10 & 0.10 \\
\hline$(0.05)$ & $(0.04)$ & $(0.07)$ & $(0.04)$ & $(0.03)$ & $(0.03)$ & $(0.02)$ \\
\hline $\begin{array}{l}-0.02 \\
(0.01)\end{array}$ & $\begin{array}{c}0.00 \\
(0.00)\end{array}$ & $\begin{array}{c}0.00 \\
(0.00)\end{array}$ & $\begin{array}{c}0.00 \\
(0.01)\end{array}$ & $\begin{array}{c}0.01 \\
(0.01)\end{array}$ & $\begin{array}{l}-0.01 \\
(0.00)\end{array}$ & $\begin{array}{c}0.00 \\
(0.00)\end{array}$ \\
\hline 1,709 & 1,244 & 846 & 814 & 855 & 787 & 6,255 \\
\hline \multicolumn{7}{|c|}{ Full Sample } \\
\hline-0.09 & 0.04 & 0.14 & 0.17 & 0.18 & 0.20 & 0.11 \\
\hline$(0.02)$ & $(0.02)$ & $(0.01)$ & $(0.02)$ & $(0.01)$ & $(0.01)$ & $(0.01)$ \\
\hline 0.00 & 0.00 & 0.00 & -0.01 & 0.00 & 0.00 & 0.00 \\
\hline$(0.00)$ & $(0.00)$ & $(0.00)$ & $(0.00)$ & $(0.00)$ & $(0.00)$ & $(0.00)$ \\
\hline 0.12 & 0.06 & 0.06 & 0.04 & 0.04 & 0.03 & 0.05 \\
\hline$(0.01)$ & $(0.01)$ & $(0.01)$ & $(0.01)$ & $(0.01)$ & $(0.01)$ & $(0.00)$ \\
\hline 9,204 & 9,109 & 10,288 & 9,716 & 10,220 & 9,190 & 57,727 \\
\hline
\end{tabular}

Number of Kids Aged 7 to 15

Attending School

Number of Kids not Attending

Due to Lack of School Fees

Number of Kids Under 7

In Daycare

Number of Observations

The sample includes black mothers aged 20 to 45 whose youngest child is aged within 2 years of the age eligibility cutoff. The table reports the coefficient on having an age eligible child in a specification which controls for household income, or the coefficient on individual report of grant receipt. Standard Errors are reported in parentheses. The specification includes age, years of education, a marital status dummy, household income (based on salaries and pensions), province dummies, number of children, and number of children aged under 7. Clustering by PSU does not change the results significantly. The pooled sample includes years 2005, 2006, 2007, 2008. 
Appendix Table 7: Balancing Characteristics Across the Age Limits, by Year

\begin{tabular}{|c|c|c|c|c|c|c|c|}
\hline $\begin{array}{l}\overline{\text { Year }} \\
\text { Age Limit }\end{array}$ & $\begin{array}{c}2002 \\
7 \\
(1) \\
\end{array}$ & $\begin{array}{c}2003 \\
9 \\
(2) \\
\end{array}$ & $\begin{array}{c}2004 \\
11 \\
(3) \\
\end{array}$ & $\begin{array}{c}2005 \\
14 \\
(4) \\
\end{array}$ & $\begin{array}{c}2006 \\
14 \\
(5) \\
\end{array}$ & $\begin{array}{c}2007 \\
14 \\
(6) \\
\end{array}$ & $\begin{array}{c}2008 \\
14 \\
(7) \\
\end{array}$ \\
\hline Age & $\begin{array}{l}-1.63 \\
-6.22\end{array}$ & $\begin{array}{l}-1.05 \\
-3.71\end{array}$ & $\begin{array}{l}-1.25 \\
-3.93\end{array}$ & $\begin{array}{l}-0.98 \\
-2.91\end{array}$ & $\begin{array}{l}-0.72 \\
-2.44\end{array}$ & $\begin{array}{l}-0.57 \\
-1.57\end{array}$ & $\begin{array}{l}-0.89 \\
-2.49\end{array}$ \\
\hline Years Education & $\begin{array}{l}0.01 \\
0.08\end{array}$ & $\begin{array}{l}0.13 \\
0.64\end{array}$ & $\begin{array}{l}0.23 \\
0.98\end{array}$ & $\begin{array}{l}0.26 \\
0.87\end{array}$ & $\begin{array}{l}0.33 \\
0.94\end{array}$ & $\begin{array}{l}-0.41 \\
-1.48\end{array}$ & $\begin{array}{l}-0.15 \\
-0.53\end{array}$ \\
\hline Married & $\begin{array}{l}0.00 \\
-0.08\end{array}$ & $\begin{array}{l}0.01 \\
0.38\end{array}$ & $\begin{array}{l}-0.01 \\
-0.42\end{array}$ & $\begin{array}{l}-0.05 \\
-1.58\end{array}$ & $\begin{array}{l}0.05 \\
1.34\end{array}$ & $\begin{array}{l}0.01 \\
0.28\end{array}$ & $\begin{array}{l}-0.01 \\
-0.16\end{array}$ \\
\hline Household Size & $\begin{array}{l}0.14 \\
1.04\end{array}$ & $\begin{array}{l}0.11 \\
0.83\end{array}$ & $\begin{array}{l}0.20 \\
1.33\end{array}$ & $\begin{array}{l}0.24 \\
1.24\end{array}$ & $\begin{array}{l}0.19 \\
0.96\end{array}$ & $\begin{array}{l}0.45 \\
2.52\end{array}$ & $\begin{array}{l}0.00 \\
0.02\end{array}$ \\
\hline Number of Kids & $\begin{array}{l}0.08 \\
1.40\end{array}$ & $\begin{array}{l}0.11 \\
1.71\end{array}$ & $\begin{array}{l}0.13 \\
1.82\end{array}$ & $\begin{array}{l}0.24 \\
3.25\end{array}$ & $\begin{array}{l}0.21 \\
2.95\end{array}$ & $\begin{array}{l}0.20 \\
3.05\end{array}$ & $\begin{array}{l}0.18 \\
2.33\end{array}$ \\
\hline Household Income & $\begin{array}{l}-155.65 \\
-1.02\end{array}$ & $\begin{array}{c}-165.44 \\
-1.04\end{array}$ & $\begin{array}{l}-10.25 \\
-0.04\end{array}$ & $\begin{array}{c}268.19 \\
1.03\end{array}$ & $\begin{array}{c}200.32 \\
0.95\end{array}$ & $\begin{array}{l}-845.17 \\
-2.25\end{array}$ & $\begin{array}{l}-283.99 \\
-0.78\end{array}$ \\
\hline $\begin{array}{l}\text { Labour Force Participant } \\
\text { (Broad) }\end{array}$ & $\begin{array}{l}-0.03 \\
-1.85\end{array}$ & $\begin{array}{l}0.01 \\
0.54\end{array}$ & $\begin{array}{l}0.02 \\
0.82\end{array}$ & $\begin{array}{l}0.05 \\
1.81\end{array}$ & $\begin{array}{l}0.01 \\
0.38\end{array}$ & $\begin{array}{l}0.02 \\
0.65\end{array}$ & $\begin{array}{l}-0.01 \\
-0.28\end{array}$ \\
\hline $\begin{array}{l}\text { Unemployed (Broad) } \\
\text { Conditional on Participation }\end{array}$ & $\begin{array}{l}0.07 \\
3.04\end{array}$ & $\begin{array}{l}0.00 \\
0.00\end{array}$ & $\begin{array}{l}0.01 \\
0.21\end{array}$ & $\begin{array}{l}0.01 \\
0.32\end{array}$ & $\begin{array}{l}0.03 \\
0.80\end{array}$ & $\begin{array}{l}0.07 \\
2.09\end{array}$ & $\begin{array}{l}0.11 \\
2.69\end{array}$ \\
\hline Employed & $\begin{array}{l}-0.07 \\
-3.48\end{array}$ & $\begin{array}{l}0.00 \\
0.20\end{array}$ & $\begin{array}{l}0.00 \\
0.13\end{array}$ & $\begin{array}{l}0.02 \\
0.61\end{array}$ & $\begin{array}{l}-0.02 \\
-0.68\end{array}$ & $\begin{array}{l}-0.04 \\
-1.42\end{array}$ & $\begin{array}{l}-0.09 \\
-2.50\end{array}$ \\
\hline $\begin{array}{l}\text { \# Treatment Group } \\
\text { \# Control Group } \\
\text { Number of Observations }\end{array}$ & $\begin{array}{l}1,360 \\
1,021 \\
2,381 \\
\end{array}$ & $\begin{array}{c}965 \\
753 \\
1,718 \\
\end{array}$ & $\begin{array}{c}704 \\
551 \\
1,255 \\
\end{array}$ & $\begin{array}{l}508 \\
345 \\
853 \\
\end{array}$ & $\begin{array}{l}481 \\
339 \\
820 \\
\end{array}$ & $\begin{array}{l}501 \\
361 \\
862 \\
\end{array}$ & $\begin{array}{l}458 \\
336 \\
794 \\
\end{array}$ \\
\hline
\end{tabular}

This table reports the difference coefficient between treated and control, in each year, for the plus minus 2 sample. T statistics on this difference are reported in italics below the difference coefficient. We can see for instance in 2002, woman who had an eligible child were on average 1.75 years younger than women who did not, and this difference is significant. 
Appendix Table 8: Balancing Tests across the Age Ranges

\begin{tabular}{|c|c|c|c|c|c|c|c|c|}
\hline & \multicolumn{2}{|c|}{$\begin{array}{c}\text { Aged under 7: } \\
\text { pre } 2002\end{array}$} & \multicolumn{2}{|c|}{$\begin{array}{c}\text { Aged under 9: } \\
2003\end{array}$} & \multicolumn{2}{|c|}{ Aged under 11: 2004} & \multicolumn{2}{|c|}{$\begin{array}{l}\text { Aged under 14: } \\
2005-2008\end{array}$} \\
\hline & Control & T-C Diff & Control & T-C Diff & Control & T-C Diff & Control & T-C Diff \\
\hline & $(1)$ & $(2)$ & (3) & $(4)$ & $(5)$ & $(6)$ & $(7)$ & $(8)$ \\
\hline Age & $\begin{array}{l}34.24 \\
(0.25)\end{array}$ & $\begin{array}{l}-0.89 \\
-2.80\end{array}$ & $\begin{array}{l}35.87 \\
(0.33)\end{array}$ & $\begin{array}{l}-0.71 \\
-1.72\end{array}$ & $\begin{array}{l}37.09 \\
(0.33)\end{array}$ & $\begin{array}{l}-0.83 \\
-1.91\end{array}$ & $\begin{array}{l}38.75 \\
(0.34)\end{array}$ & $\begin{array}{l}-0.87 \\
-1.79\end{array}$ \\
\hline Years Education & $\begin{array}{l}8.63 \\
(0.17)\end{array}$ & $\begin{array}{l}-0.06 \\
-0.29\end{array}$ & $\begin{array}{l}8.42 \\
(0.23)\end{array}$ & $\begin{array}{l}-0.23 \\
-0.77\end{array}$ & $\begin{array}{l}8.36 \\
(0.27)\end{array}$ & $\begin{array}{l}-0.42 \\
-1.21\end{array}$ & $\begin{array}{l}7.46 \\
(0.30)\end{array}$ & $\begin{array}{l}0.31 \\
0.73\end{array}$ \\
\hline Married & $\begin{array}{c}0.47 \\
(0.02)\end{array}$ & $\begin{array}{l}0.01 \\
0.55\end{array}$ & $\begin{array}{c}0.49 \\
(0.03)\end{array}$ & $\begin{array}{l}0.04 \\
1.29\end{array}$ & $\begin{array}{c}0.48 \\
(0.03)\end{array}$ & $\begin{array}{l}0.03 \\
0.67\end{array}$ & $\begin{array}{l}0.47 \\
(0.04)\end{array}$ & $\begin{array}{l}0.02 \\
0.52\end{array}$ \\
\hline Household Size & $\begin{array}{l}6.43 \\
(0.12)\end{array}$ & $\begin{array}{l}-0.12 \\
-0.83\end{array}$ & $\begin{array}{c}6.34 \\
(0.16)\end{array}$ & $\begin{array}{l}-0.31 \\
-1.63\end{array}$ & $\begin{array}{c}6.54 \\
(0.20)\end{array}$ & $\begin{array}{l}-0.53 \\
-2.09\end{array}$ & $\begin{array}{l}5.78 \\
(0.24)\end{array}$ & $\begin{array}{l}0.02 \\
0.06\end{array}$ \\
\hline Number of Kids & $\begin{array}{l}2.65 \\
(0.06)\end{array}$ & $\begin{array}{l}-0.09 \\
-1.03\end{array}$ & $\begin{array}{l}2.61 \\
(0.08)\end{array}$ & $\begin{array}{l}0.08 \\
0.70\end{array}$ & $\begin{array}{l}2.39 \\
(0.08)\end{array}$ & $\begin{array}{l}0.04 \\
0.41\end{array}$ & $\begin{array}{c}2.24 \\
(0.10)\end{array}$ & $\begin{array}{l}0.00 \\
0.00\end{array}$ \\
\hline Household Income & $\begin{array}{l}1,395.0 \\
(95.02)\end{array}$ & $\begin{array}{l}-30.1 \\
-0.29\end{array}$ & $\begin{array}{c}1,488.4 \\
(117.50)\end{array}$ & $\begin{array}{l}-255.3 \\
-1.83\end{array}$ & $\begin{array}{l}1,554.7 \\
(141.01)\end{array}$ & $\begin{array}{l}-221.7 \\
-1.32\end{array}$ & $\begin{array}{l}1,624.8 \\
(178.58)\end{array}$ & $\begin{array}{l}-188.2 \\
-0.86\end{array}$ \\
\hline $\begin{array}{l}\text { Labour Force Participant } \\
\text { (Broad Definition) }\end{array}$ & $\begin{array}{l}0.69 \\
(0.02)\end{array}$ & $\begin{array}{l}0.00 \\
0.12\end{array}$ & $\begin{array}{l}0.73 \\
(0.02)\end{array}$ & $\begin{array}{l}-0.02 \\
-0.69\end{array}$ & $\begin{array}{c}0.76 \\
(0.03)\end{array}$ & $\begin{array}{l}-0.07 \\
-2.16\end{array}$ & $\begin{array}{c}0.74 \\
(0.03)\end{array}$ & $\begin{array}{l}-0.01 \\
-0.21\end{array}$ \\
\hline $\begin{array}{l}\text { Unemployed (Broad } \\
\text { Definition) }\end{array}$ & $\begin{array}{c}0.49 \\
(0.03)\end{array}$ & $\begin{array}{l}0.02 \\
0.70\end{array}$ & $\begin{array}{c}0.50 \\
(0.03)\end{array}$ & $\begin{array}{l}0.01 \\
0.28\end{array}$ & $\begin{array}{c}0.47 \\
(0.03)\end{array}$ & $\begin{array}{l}0.06 \\
1.26\end{array}$ & $\begin{array}{l}0.42 \\
(0.04)\end{array}$ & $\begin{array}{l}-0.07 \\
-1.20\end{array}$ \\
\hline Employed & $\begin{array}{c}0.35 \\
(0.02)\end{array}$ & $\begin{array}{l}-0.01 \\
-0.56\end{array}$ & $\begin{array}{c}0.37 \\
(0.03)\end{array}$ & $\begin{array}{l}-0.02 \\
-0.56\end{array}$ & $\begin{array}{c}0.40 \\
(0.03)\end{array}$ & $\begin{array}{l}-0.08 \\
-2.16\end{array}$ & $\begin{array}{c}0.43 \\
(0.04)\end{array}$ & $\begin{array}{l}0.05 \\
0.94\end{array}$ \\
\hline \# Treatment Group & \multicolumn{2}{|c|}{1,609} & \multicolumn{2}{|c|}{1,088} & \multicolumn{2}{|c|}{789} & \multicolumn{2}{|c|}{491} \\
\hline \# Control Group & \multicolumn{2}{|c|}{1,088} & \multicolumn{2}{|c|}{789} & \multicolumn{2}{|c|}{564} & \multicolumn{2}{|c|}{349} \\
\hline Number of Observations & \multicolumn{2}{|c|}{2,697} & \multicolumn{2}{|c|}{1,877} & \multicolumn{2}{|c|}{1,353} & \multicolumn{2}{|c|}{840} \\
\hline
\end{tabular}

Balancing tests are performed in the year 1997, pre-treatment. Each sample consists of black mothers, aged 20 to 45, whose youngest child is aged within 2 years of the age eligibility cutoff. The T statistic is reported below the Treatment Control Difference. Robust Standard Errors are reported in parentheses. Clustering is performed at the psu level. 
Appendix Table 9: Labour Market Outcomes - Level Estimates of the Age Eligibility Effect

Age Limit

\begin{tabular}{|c|c|c|c|c|c|c|c|c|}
\hline \multirow{2}{*}{$\frac{\text { Placebo }}{1997}$} & \multicolumn{8}{|c|}{ Treatment } \\
\hline & 2002 & 2003 & 2004 & 2005 & 2006 & 2007 & 2008 & Pooled \\
\hline 0 & 7 & 9 & 11 & 14 & 14 & 14 & 14 & 14 \\
\hline (1) & (2) & (3) & (4) & (5) & (6) & (7) & (8) & (9) \\
\hline \multicolumn{9}{|c|}{ Plus Minus 2 Sample } \\
\hline $\begin{array}{c}0.00 \\
(0.02)\end{array}$ & $\begin{array}{c}-0.02 \\
(0.01)\end{array}$ & $\begin{array}{c}0.01 \\
(0.02)\end{array}$ & $\begin{array}{c}0.01 \\
(0.02)\end{array}$ & $\begin{array}{c}0.04 \\
(0.03)\end{array}$ & $\begin{array}{c}0.00 \\
(0.03)\end{array}$ & $\begin{array}{c}0.03 \\
(0.03)\end{array}$ & $\begin{array}{c}0.00 \\
(0.03)\end{array}$ & $\begin{array}{c}0.02 \\
(0.01)\end{array}$ \\
\hline $\begin{array}{l}-0.04 \\
(0.03)\end{array}$ & $\begin{array}{c}0.03 \\
(0.02)\end{array}$ & $\begin{array}{l}-0.02 \\
(0.02)\end{array}$ & $\begin{array}{l}-0.01 \\
(0.03)\end{array}$ & $\begin{array}{c}0.01 \\
(0.04)\end{array}$ & $\begin{array}{c}0.01 \\
(0.03)\end{array}$ & $\begin{array}{c}0.03 \\
(0.03)\end{array}$ & $\begin{array}{c}0.09 \\
(0.04)\end{array}$ & $\begin{array}{c}0.03 \\
(0.02)\end{array}$ \\
\hline $\begin{array}{c}0.03 \\
(0.02)\end{array}$ & $\begin{array}{l}-0.03 \\
(0.02)\end{array}$ & $\begin{array}{c}0.03 \\
(0.02)\end{array}$ & $\begin{array}{c}0.02 \\
(0.03)\end{array}$ & $\begin{array}{c}0.02 \\
(0.03)\end{array}$ & $\begin{array}{l}-0.01 \\
(0.03)\end{array}$ & $\begin{array}{l}-0.01 \\
(0.03)\end{array}$ & $\begin{array}{l}-0.07 \\
(0.03)\end{array}$ & $\begin{array}{l}-0.01 \\
(0.02)\end{array}$ \\
\hline 1,873 & 2,368 & 1,710 & 1,246 & 846 & 815 & 858 & 789 & 3,308 \\
\hline \multicolumn{9}{|c|}{ Full Sample } \\
\hline $\begin{array}{l}-0.01 \\
(0.01)\end{array}$ & $\begin{array}{c}-0.02 \\
(0.01)\end{array}$ & $\begin{array}{c}0.01 \\
(0.01)\end{array}$ & $\begin{array}{c}0.03 \\
(0.01)\end{array}$ & $\begin{array}{c}0.05 \\
(0.01)\end{array}$ & $\begin{array}{c}0.02 \\
(0.01)\end{array}$ & $\begin{array}{c}0.05 \\
(0.01)\end{array}$ & $\begin{array}{c}0.04 \\
(0.01)\end{array}$ & $\begin{array}{c}0.04 \\
(0.01)\end{array}$ \\
\hline $\begin{array}{c}0.04 \\
(0.01)\end{array}$ & $\begin{array}{c}0.05 \\
(0.01)\end{array}$ & $\begin{array}{c}0.05 \\
(0.01)\end{array}$ & $\begin{array}{c}0.05 \\
(0.02)\end{array}$ & $\begin{array}{c}0.06 \\
(0.02)\end{array}$ & $\begin{array}{c}0.09 \\
(0.02)\end{array}$ & $\begin{array}{c}0.08 \\
(0.02)\end{array}$ & $\begin{array}{c}0.06 \\
(0.02)\end{array}$ & $\begin{array}{c}0.07 \\
(0.01)\end{array}$ \\
\hline-0.04 & -0.05 & -0.04 & -0.03 & -0.03 & -0.07 & -0.05 & -0.03 & -0.04 \\
\hline$(0.01)$ & $(0.01)$ & $(0.01)$ & $(0.01)$ & $(0.02)$ & $(0.02)$ & $(0.01)$ & $(0.02)$ & $(0.01)$ \\
\hline 12,198 & 9,683 & 9,211 & 9,114 & 10,301 & 9,730 & 10,249 & 9,233 & 39,513 \\
\hline
\end{tabular}

Labour Force Participant

(Broad)

Unemployed (Broad)

Conditional on Participation

Employed

Number of Observations

Labour Force Participant

(Broad)

Unemployed (Broad)

Conditional on Participation

Employed

Number of Observations

12,198

The sample includes black mothers aged 20 to 45 . The table reports the coefficient on having an age eligible child in a specification
which controls for household income, or the coefficient on individual report of grant receipt. Standard Errors are reported in parentheses.

The specification includes age, years of education, a marital status dummy, household income (based on salaries and pensions), province dummies. Clustering by PSU does not change the results significantly. The pooled sample includes years 2005, 2006, 2007, 2008. 
Appendix Table 10: Sample Means

\begin{tabular}{|c|c|c|c|c|c|c|c|c|c|}
\hline & $\begin{array}{c}1997 \\
(1) \\
\end{array}$ & $\begin{array}{c}1998 \\
(2) \\
\end{array}$ & $\begin{array}{c}2002 \\
(3) \\
\end{array}$ & $\begin{array}{c}2003 \\
(4) \\
\end{array}$ & $\begin{array}{c}2004 \\
(5) \\
\end{array}$ & $\begin{array}{c}2005 \\
(6) \\
\end{array}$ & $\begin{array}{c}2006 \\
(7) \\
\end{array}$ & $\begin{array}{c}2007 \\
(8) \\
\end{array}$ & $\begin{array}{c}2008 \\
(9) \\
\end{array}$ \\
\hline Age & $\begin{array}{l}32.79 \\
(7.08)\end{array}$ & $\begin{array}{l}32.47 \\
(7.06)\end{array}$ & $\begin{array}{l}32.70 \\
(7.10)\end{array}$ & $\begin{array}{l}33.05 \\
(7.17)\end{array}$ & $\begin{array}{l}33.04 \\
(7.24)\end{array}$ & $\begin{array}{l}32.70 \\
(7.23)\end{array}$ & $\begin{array}{l}32.91 \\
(7.23)\end{array}$ & $\begin{array}{l}32.83 \\
(7.28)\end{array}$ & $\begin{array}{l}32.67 \\
(7.35)\end{array}$ \\
\hline Years Education & $\begin{array}{c}8.47 \\
(4.12)\end{array}$ & $\begin{array}{c}8.59 \\
(4.16)\end{array}$ & $\begin{array}{c}8.66 \\
(3.86)\end{array}$ & $\begin{array}{c}8.82 \\
(3.85)\end{array}$ & $\begin{array}{c}9.00 \\
(3.73)\end{array}$ & $\begin{array}{c}8.61 \\
(3.82)\end{array}$ & $\begin{array}{c}8.70 \\
(3.79)\end{array}$ & $\begin{array}{c}8.91 \\
(3.71)\end{array}$ & $\begin{array}{c}9.29 \\
(3.54)\end{array}$ \\
\hline Married & $\begin{array}{c}0.49 \\
(0.50)\end{array}$ & $\begin{array}{c}0.46 \\
(0.50)\end{array}$ & $\begin{array}{c}0.49 \\
(0.50)\end{array}$ & $\begin{array}{c}0.49 \\
(0.50)\end{array}$ & $\begin{array}{c}0.47 \\
(0.50)\end{array}$ & $\begin{array}{c}0.46 \\
(0.50)\end{array}$ & $\begin{array}{c}0.46 \\
(0.50)\end{array}$ & $\begin{array}{c}0.44 \\
(0.50)\end{array}$ & $\begin{array}{c}0.44 \\
(0.50)\end{array}$ \\
\hline Household Size & $\begin{array}{c}6.42 \\
(3.07)\end{array}$ & $\begin{array}{c}6.29 \\
(3.03)\end{array}$ & $\begin{array}{c}6.27 \\
(3.10)\end{array}$ & $\begin{array}{c}6.06 \\
(2.87)\end{array}$ & $\begin{array}{c}6.01 \\
(2.91)\end{array}$ & $\begin{array}{c}5.99 \\
(2.85)\end{array}$ & $\begin{array}{c}5.77 \\
(2.69)\end{array}$ & $\begin{array}{c}5.89 \\
(2.79)\end{array}$ & $\begin{array}{c}5.84 \\
(2.81)\end{array}$ \\
\hline Number of Kids & $\begin{array}{c}2.56 \\
(1.60)\end{array}$ & $\begin{array}{c}2.41 \\
(1.51)\end{array}$ & $\begin{array}{c}2.25 \\
(1.45)\end{array}$ & $\begin{array}{c}2.27 \\
(1.45)\end{array}$ & $\begin{array}{c}2.21 \\
(1.41)\end{array}$ & $\begin{array}{c}2.20 \\
(1.40)\end{array}$ & $\begin{array}{c}2.19 \\
(1.39)\end{array}$ & $\begin{array}{c}2.17 \\
(1.35)\end{array}$ & $\begin{array}{c}2.10 \\
(1.29)\end{array}$ \\
\hline Household Income & $\begin{array}{c}1,282.4 \\
(1974.9)\end{array}$ & $\begin{array}{c}1,442.5 \\
(3501.2)\end{array}$ & $\begin{array}{c}1,685.6 \\
(3078.6)\end{array}$ & $\begin{array}{c}1,839.3 \\
(3336.7)\end{array}$ & $\begin{array}{c}2,032.7 \\
(4443.4)\end{array}$ & $\begin{array}{c}1,847.0 \\
(3501.8)\end{array}$ & $\begin{array}{c}1,997.3 \\
(4065.3)\end{array}$ & $\begin{array}{c}2,335.5 \\
(4447.5)\end{array}$ & $\begin{array}{c}2,948.3 \\
(13454.2)\end{array}$ \\
\hline $\begin{array}{l}\text { Labour Force Participant } \\
\text { (Broad) }\end{array}$ & $\begin{array}{c}0.65 \\
(0.48)\end{array}$ & $\begin{array}{c}0.68 \\
(0.47)\end{array}$ & $\begin{array}{c}0.82 \\
(0.39)\end{array}$ & $\begin{array}{c}0.80 \\
(0.40)\end{array}$ & $\begin{array}{c}0.81 \\
(0.39)\end{array}$ & $\begin{array}{c}0.77 \\
(0.42)\end{array}$ & $\begin{array}{c}0.78 \\
(0.42)\end{array}$ & $\begin{array}{c}0.77 \\
(0.42)\end{array}$ & $\begin{array}{c}0.78 \\
(0.42)\end{array}$ \\
\hline $\begin{array}{l}\text { Unemployed (Broad) } \\
\text { Conditional on Participation }\end{array}$ & $\begin{array}{c}0.56 \\
(0.50)\end{array}$ & $\begin{array}{c}0.56 \\
(0.50)\end{array}$ & $\begin{array}{l}0.58 \\
(0.49)\end{array}$ & $\begin{array}{c}0.59 \\
(0.49)\end{array}$ & $\begin{array}{c}0.59 \\
(0.49)\end{array}$ & $\begin{array}{c}0.60 \\
(0.49)\end{array}$ & $\begin{array}{c}0.60 \\
(0.49)\end{array}$ & $\begin{array}{c}0.58 \\
(0.49)\end{array}$ & $\begin{array}{c}0.56 \\
(0.50)\end{array}$ \\
\hline Employed & $\begin{array}{l}0.28 \\
(0.45)\end{array}$ & $\begin{array}{l}0.30 \\
(0.46)\end{array}$ & $\begin{array}{c}0.35 \\
(0.48)\end{array}$ & $\begin{array}{c}0.33 \\
(0.47)\end{array}$ & $\begin{array}{c}0.33 \\
(0.47)\end{array}$ & $\begin{array}{c}0.31 \\
(0.46)\end{array}$ & $\begin{array}{c}0.31 \\
(0.46)\end{array}$ & $\begin{array}{c}0.33 \\
(0.47)\end{array}$ & $\begin{array}{c}0.35 \\
(0.48)\end{array}$ \\
\hline \# Treatment Group & 8,422 & 5,283 & 6,358 & 6,814 & 7,410 & 9,359 & 8,760 & 9,263 & 8,286 \\
\hline \# Control Group & 3,800 & 2,466 & 3,367 & 2,447 & 1,749 & 990 & 992 & 1,013 & 991 \\
\hline Number of Observations & 12,222 & 7,749 & 9,725 & 9,261 & 9,159 & 10,349 & 9,752 & 10,276 & 9,277 \\
\hline
\end{tabular}

The sample includes black women aged between 20 and 45 . Standard deviations are reported in parentheses. 
Appendix Table 11: Grant Amounts, Adjustment Dates, and Age Limits

\begin{tabular}{|c|c|c|c|c|}
\hline$\overline{\overline{\text { Date }}}$ & Old Age \& Disabilty Grant & Foster Care & State Maintenance & Age Limits \\
\hline 93/09 - 94/09 & R 370 & R 260 & R115 & \\
\hline $94 / 10-95 / 06$ & R 390 & R 274 & R121 & \\
\hline 95/07 - 96/05 & R 410 & R 288 & $\mathrm{R} 127$ & \\
\hline $96 / 06-97 / 06$ & R 430 & R 305 & R135 & \\
\hline $97 / 07-98 / 06$ & R 470 & R 340 & & \\
\hline 98/07 - 98/09 & R 490 & R 350 & CSG & CSG \\
\hline $98 / 10-99 / 06$ & R 500 & R 360 & R 100 & 7 \\
\hline 1 July 1999 & R 520 & R 374 & R 100 & 7 \\
\hline 1 July 2000 & R 540 & R 390 & R 100 & 7 \\
\hline 1 July 2001 & R 570 & R 410 & R 110 & 7 \\
\hline 1 April 2002 & R 620 & R 450 & R 130 & 7 \\
\hline 1 October 2002 & R 640 & R 460 & R 140 & 7 \\
\hline 1 April 2003 & R 700 & R 500 & R 160 & 9 \\
\hline 1 April 2004 & R 740 & R 530 & R 170 & 11 \\
\hline 1 April 2005 & R 780 & R 560 & R 180 & 14 \\
\hline 1 April 2006 & R 820 & R 590 & R 190 & 14 \\
\hline 1 April 2007 & R 870 & R 620 & R 200 & 14 \\
\hline 1 April 2008 & R 940 & R 630 & R 210 & 14 \\
\hline 22 August 2008 & R 960 & R 650 & R 230 & 14 \\
\hline 1 April 2009 & R 1,010 & R 680 & R 240 & 15 \\
\hline 1 April 2010 & R 1,080 & R 710 & R 250 & 16 \\
\hline
\end{tabular}

